\title{
DEL ARADO CRIOLLO AL GRANERO DEL MUNDO. LA TRANSFORMACIÓN TECNOLÓGICA DE LA AGRICULTURA PAMPEANA ARGENTINA, 1840-1900
}

\author{
Julio Djenderedjian \\ Instituto Ravignani, Universidad de Buenos Aires, \\ Consejo Nacional de Investigaciones Científicas y Técnicas
}

Es s bastante llamativo que la historia de la tecnología agraria del siglo XIX haya sido en Argentina un campo relativamente descuidado hasta tiempos recientes. ${ }^{1}$ Ello es raro porque se trata justamente del periodo clave en el que la actividad cambió por

Fecha de recepción: 25 de marzo de 2019

Fecha de aceptación: 12 de agosto de 2019

1 Parte de los estudios se centró lógicamente en la mecanización: Carlos De Dios, "Historia de las máquinas de cosecha" [manuscrito, Buenos Aires], 1984; Bearzotti, El proceso; Frank, Trigo y trabajo. Más recientemente, SESTO, Una genética, o AlAPIN, Rastrojos, elaboraron análisis integrales sobre procesos puntuales; el periodo colonial y la primera mitad del siglo XIX aún requieren más investigaciones: Garavaglia, Pastores y labradores, pp. 182-200, o DJENDEREDJIAN, La agricultura pampeana, pp. 87-132 y 245-288. Un largo y por momentos engorroso debate se entabló hace tiempo sobre un supuesto retraso tecnológico (y consiguiente estancamiento productivo) en la agricultura pampeana del siglo xx, atribuyéndolo a rigideces en la estructura agraria y poco compromiso con la inversión; J. F. Sabato extendió esos problemas incluso al siglo XIx, y J. Adelman en parte los justificó en un diferencial acceso al capital. Pero desde los aportes de Cortés Conde, El progreso, sabemos que esa estructura agraria era dinámica, y desde BARsky, CiAfardini y Cristiá, Producción, que ese estancamiento es algo muy discutible, por lo que ese debate perdió sentido. Puede verse al respecto Miguez, "La expansión”, pp. 89-119. 
completo, avanzando sobre un aprovechamiento más integral de los recursos disponibles, y modificando, hasta la actualidad, el balance del producto. Si en el siglo xx la Argentina ha sido uno de los mayores exportadores mundiales de granos y oleaginosas, no está de más recordar que, hasta 1880 , fue un importador neto de ellos, escandalizando a los publicistas de la época. ${ }^{2}$

Este artículo expone la compleja evolución del proceso de transformación de la agricultura pampeana, desde la agricultura criolla, a muy pequeña escala, con instrumentos limitados, desarrollada en ambientes húmedos y centrada en el abasto a mercados locales, hasta la agricultura moderna, orientada hacia el mercado mundial, extensiva, llevada a cabo en áreas de frontera, y con incorporación de maquinaria y semillas mejoradas. Suele pensarse que ese cambio comenzó con el establecimiento de las primeras colonias agrícolas de inmigrantes extranjeros, fenómeno bastante tardío en Argentina en comparación con sus naciones vecinas. ${ }^{3}$ En realidad, el tema es mucho más complejo, y en todo caso, la transformación excedió con mucho a su ámbito, superando desde ya la misma área pampeana, puesto que dialogó permanentemente con sistemas globales de innovación, tanto en el Viejo como en el Nuevo Mundo. Ese intercambio no fue unidireccional; la construcción de nuevos hitos tecnológicos útiles para la región pampeana exigía que tuvieran características propias, y por tanto, no se trataba en modo alguno de trasplantar simplemente procesos y maquinaria desde esas otras economías agrarias. Por lo demás, los desarrollos y las características propias registrados localmente impactaron en la oferta de maquinaria importada, provocando incluso la creación de

${ }^{2}$ Uno de ellos recordaba que "jla harina venía de Francia, de Alemania, de California, hasta de Australia!”. CARRASco, Intereses nacionales, p. 130.

${ }^{3}$ En Brasil, las colonias de inmigrantes comenzaron en 1824 y fueron modelo de las primeras instaladas en Argentina; en Chile, los emprendimientos se iniciaron en la década de 1840. La primera colonia argentina concretada data de 1853. Roche, La colonisation; BlancPain, Les allemands. 
modelos específicos para cubrirla, que se sumaban a la oferta de fabricación local y competían con ella. ${ }^{4}$ De ese modo, en lo que respecta a la transformación tecnológica de la agricultura pampeana, el papel de las colonias agrícolas sólo puede comprenderse cabalmente si se tiene en cuenta la sinergia que generaron en la creación de un nuevo paradigma; desde ya, ese papel fue fundamental porque las tuvo como protagonistas de enorme relevancia, sobre todo en el periodo de más intenso cambio y afianzamiento del nuevo sistema de innovación agrícola, en torno al tercer cuarto del siglo XIX. Es por ello paradójico que ese papel aún esté prácticamente en las sombras. ${ }^{5}$

Las pautas propias de las primeras colonias agrícolas -en alguna medida similares a las de los emprendimientos brasileños y chilenos que las habían inspirado- resultaron muy diferentes a éstas. En esas primeras colonias, de producción variada, se operaba en pequeña escala y los excedentes agrícolas eran cortos, se volcaban en mercados locales y regionales bajo pautas de calidad

${ }^{4}$ Las referencias explícitas a soluciones encaradas en distintos países del mundo, y los estudios comparados, son una constante en las fuentes. Varias misiones de estudio fueron enviadas a diversos países y se prestaba atención a los informes resultantes. Una sola de esas misiones publicó diez volúmenes de informes entre 1882 y 1884. Newton y Llerena, Viajes y estudios. Los desarrollos mecánicos locales incluyeron adaptaciones creativas de los elementos y procesos de las máquinas originales (como ocurrió por ejemplo con la segadora y acarreadora Colombo), cambios que fueron rápidamente registrados por las grandes empresas internacionales fabricantes de maquinaria agrícola, que adaptaron sus modelos a las pampas incorporando esos desarrollos locales, incluso diseñando maquinaria de gran porte especialmente para el mercado argentino, por ejemplo la cosechadora Deering-McCormick 31-B. Sobre la Colombo véase Frank, Trigo y trabajo, pp. 152-154; sobre la cosechadora Deering-McCormick, Carlos De Dios, "Historia de las máquinas de cosecha" [manuscrito, Buenos Aires], 1984, p. 89.

${ }^{5}$ No hay aún análisis profundos del papel de las colonias argentinas como nodos de innovación, ni tampoco un relato pormenorizado de los cambios en la tecnología agrícola que empleaban. Ello contrasta con la historiografía canadiense y la brasileña. BOUCHARD, Quelques arpents, o SEYFERTH, A colonização. 
básicas y tradicionales. Pero pronto se comenzó a construir un esquema completamente nuevo basado en la especialización, la producción extensiva, las economías de escala y una orientación creciente hacia criterios de selectividad propios de los mercados de consumo europeos. ${ }^{6}$ Ese esquema, que se generalizaría en las pampas rioplatenses, tanto en las colonias como fuera de ellas, evidencia el importante papel de éstas como centros de generación y experimentación de nuevas tecnologías agrícolas. Esta visión de las colonias agrícolas diverge de la tradicional, y subraya que éstas desde un principio interactuaron notablemente con otros núcleos de la región pampeana; destacando que, si bien su papel fue fundamental en la creación y experimentación de nuevas técnicas de cultivo, esas nuevas técnicas a su vez impulsaron transformaciones fuera del ámbito territorial y comercial bajo su control, y en ese proceso el impulso para lograr innovaciones se retroalimentó también desde esos ámbitos no colonizados. Es decir, las colonias fueron parte de un entramado mucho más complejo, que supuso el agregado progresivo de nuevos núcleos o nodos de innovación que interactuaban entre sí y recibían y adaptaban información de muy diversos orígenes, mayormente empíricos, fruto de ensayos y errores, pero también, progresivamente, de aportes más formales encarados bajo pautas científicas. Desde esta perspectiva, la colonización agrícola adquiere otra relevancia y perfil, además de estar fuertemente determinada por la ecuación de costos propia de un país con abundancia de tierras y escasez y carestía de capital. En estas páginas intentaremos resumir las líneas fundamentales de ese proceso, centrándonos, por razones de espacio, en la producción de trigo y en el segmento de la siembra.

${ }^{6}$ Un ejemplo tardío de la actitud hacia los cultivos diversificados y en pequeña escala propios de la agricultura criolla tradicional en CARAVIA, Manual práctico, pp. 46-47, quien expone los argumentos típicos: ante la "gran concurrencia" propia de mercados limitados por la escasez de población, lo mejor es "poseer $[\ldots]$ varios artículos para vender sólo los que obtengan mejores valores $[\ldots]$ ”. 


\section{ALGUNOS PRESUPUESTOS TEÓRICOS}

Desde los aportes de Schumpeter, sabemos que un sistema productivo en equilibrio relativo, y por tanto atrapado en un esquema de ganancias decrecientes, puede ser desafiado por sus actores mediante la innovación, a fin de conquistar nuevos márgenes de rentabilidad; el resultado, es decir, la aparición de productos nuevos por medio de procesos también en parte o totalmente nuevos, ha estado en el centro de las discusiones sobre invención e innovación desde entonces. ${ }^{7}$ La visión predominante durante décadas, pautada por el peso de las grandes rupturas y la necesidad de encontrar y describir los vínculos entre innovación y crecimiento económico, sostenida entre otros por Joel Mokyr, ha sido desafiada en los últimos tiempos por la importancia cada vez mayor atribuida a procesos de cambio discontinuo y de naturaleza aparentemente menor, pero cuya acumulación y encadenamiento termina por producir transformaciones de amplio alcance. ${ }^{8}$

Ello llevó a su vez a desmitificar el peso de la información codificada (es decir, el inventario físico ya incorporado a la corriente circular: maquinarias, componentes, manuales operativos), revalorizando las otras herramientas necesarias para generar

\footnotetext{
7 Recordemos que para Schumpeter la búsqueda de beneficios es obra del empresario y de su capacidad innovadora. La competencia interempresarial establece una tensión dialéctica entre status quo e innovación, obligando a los actores a introducir constantes cambios a fin de lograr mantener su lugar en la oferta; esta es la esencia del proceso de "destrucción creadora". Un útil análisis al respecto en Metcalfe y Cantner, Change, pp. 145 y ss.

${ }^{8}$ Мокүr, Technological Creativity. Se relativizó así el carácter de ruptura radical asociado al concepto; en términos de Kauffman, la innovación puede también conformarse sobre "adyacentes posibles", es decir, el amplísimo abanico de posibilidades abierto por las múltiples combinaciones de un conjunto dado de factores, y cuyos resultados, aun cuando no signifiquen diferencias significativas con el punto de partida, de todos modos constituyen objetos nuevos. KaufFMAN, Investigations, pp. 49 y ss.; 141 y ss.
} 
innovaciones (esto es, los objetivos, las destrezas, los principios y los individuos ligados al proceso creativo). En otras palabras, la mera inversión de capital es vista actualmente solo como un aspecto del fenómeno, y poco dice acerca de la sinergia creadora ligada a los procesos de innovación, el desarrollo de capacidades específicas, la interacción entre individuos y nodos, la complejidad de los procesos de ensayo y error, la adaptación y readaptación de piezas y segmentos, todo lo cual no siempre quedó registrado por escrito, o es difícil de recuperar. ${ }^{9}$ Cada proceso tiene características únicas, y las variaciones regionales pueden ser muy grandes; es por ello a menudo muy difícil identificar las líneas maestras de los fenómenos de innovación tecnológica en el agro argentino antes de 1900. Es cuestionable presuponer que los sistemas difusionistas de innovación, típicos de los años finales del siglo xıx, se limitaban a replicar estaciones experimentales cuyas investigaciones, realizadas en condiciones artificiales, tenían escaso impacto en el medio; en realidad, es bastante poco lo que sabemos sobre ese impacto entre productores que muy rara vez registraban sus impresiones por escrito. En todo caso, no se trataba de sujetos pasivos, ni en lo que respecta a la recepción, procesamiento y transmisión de información, ni en lo relativo a la experimentación. ${ }^{10}$

Es a la luz de esos conceptos que, en estas páginas, buscaremos dar cuenta de los múltiples aspectos involucrados en la generación de innovaciones tecnológicas en el mundo agrario de las pampas argentinas durante el siglo XIX. Los estudios disponibles se han basado sobre todo en la medición del progresivo

\footnotetext{
9 Johnson y Lundvall, "Promoting”; BecatTini, "Del distrito industrial”. 10 El papel activo de los diversos actores involucrados en la innovación fue aceptado por Rogers, aun considerando accesos desiguales a la información; Rogers, Diffusion of Innovations, pp. 144-157. Algunos estudios recientes muestran la complejidad de la generación de innovaciones incluso entre agricultores de pequeña escala y en áreas marginales. MARTOcCI, "Cultivar al agricultor”, pp. 1-26.
} 
incremento del parque de maquinarias para resolver la cuestión, atribuyéndole así un carácter de mero trasplante, como si producir trigo o maíz en las planicies de Buenos Aires, Santa Fe o Entre Ríos fuera lo mismo que hacerlo en Illinois, Saskatchewan, o incluso en el Bajío mexicano o la Borgoña francesa. ${ }^{11}$ Por el contrario, hubo procesos no sólo adaptativos sino creativos, que debían tener en cuenta las especiales características ambientales y edafológicas del medio local, así como el costo de los recursos, a fin de construir, en función de todo ello, una ecuación productiva exitosa y comercialmente rentable. Eso no fue nada fácil, como resulta evidente por el simple hecho de que, durante muchas décadas, la producción agrícola pampeana no fue capaz de cubrir por completo las necesidades alimenticias de su población.

Sólo por dar un ejemplo, útil en el contexto de este dossier, resulta interesante referir aquí brevemente el recorrido realizado por decenas, quizá centenares, de productores para lograr finalmente semillas de trigo adecuadas para una gran expansión productiva, mucho antes de los experimentos científicos que comenzarían después de 1900. Al lado de las simientes en uso desde la época colonial, limitadas a dos o tres variedades muy laxamente definidas, seleccionadas sin mayor cuidado del conjunto indeterminado de la última cosecha y confundiéndose en la siembra los granos buenos y malos, se fueron incorporando

\footnotetext{
11 Algunos ejemplos en Adelman, “The Social Bases”, quien sólo utilizó la inversión en maquinarias para medir comparativamente los desarrollos agrarios de Argentina y Canadá; SARTELLI, "Del asombro al desencanto", cuyo análisis aparece muy sesgado por el rígido marco teórico empleado; ScobIE, Revolución, pp. 95 y ss., atado a prejuicios sin mayor base empírica; Díaz Alejandro, Ensayos, pp. 160 y ss., aunque con matices muy significativos. El cambio en la visión de un agro supuestamente retrasado en lo tecnológico, que había predominado en buena parte del siglo xx, comenzó, como se dijo en la nota 1 con los aportes de varios investigadores; sólo resta mencionar aquí a Fienup, Brannon y Fender, El desarrollo, y Pucciarelli, El capitalismo, cuyos estudios ayudaron a complejizar el análisis de esos aspectos cruciales.
} 
cuidados progresivos y más intensos, como los preservativos caseros contra las plagas o la selección natural. Después se incorporaron a la oferta variedades de rasgos más definidos, traídas de Europa en el abigarrado equipaje de los inmigrantes, o incluso recibidas por correspondencia, ensayadas y aun seleccionadas para que cubrieran las necesidades del cultivo en ambientes muy distintos de los originales. Así, una de ellas constituyó, hacia 1850, la solución integral para el despegue de la gran producción triguera pampeana. ${ }^{12}$ Pero el conjunto de variedades de semilla empleadas se fue complejizando a lo largo del último cuarto de esa centuria, resultado de la curiosidad por experimentar con ejemplares de los más diversos orígenes, según el tipo de suelo, el clima, el momento del año, el destino del producto final a obtenerse, por prevención ante riesgos (exceso o escasez de agua, acción de plagas, etc.), y muchas otras razones. Entre cinco y seis variedades, para 1880, se repartían las preferencias; pero decenas de otras se experimentaban, y sus mezclas probablemente hayan generado otras nuevas. ${ }^{13} \mathrm{La}$ creación de variedades adaptadas mediante cruzamiento y selecciones genealógicas obtenidas de esas poblaciones heterogéneas implicó esfuerzos de inmensa magnitud, hechos a fuerza de prueba y error, que la historiografía aún no ha podido dimensionar adecuadamente. ${ }^{14}$ Es por eso que estas páginas intentarán,

${ }_{12}$ El Barletta, cuya historia resumiremos luego.

13 Un excelente resumen al respecto en Daireaux, Manual, pp. 386-409. Las variedades más utilizadas, que sin embargo no desbancaban al Barletta, eran el trigo Ruso, Saldomé, Tusella [Touzelle], Francés y Húngaro. Si bien las mismas denominaciones muestran que están sobrerrepresentadas las semillas provenientes del norte de Europa, zona edáfica y climáticamente muy distinta de la pampeana, ello respondía a que en Europa estaban los clientes del producto final, por lo que la semilla debía asemejarse a esas variedades prototípicas. ${ }^{14}$ Un ejemplo en Harries y Ripoll, Semillas, pp. 3-5, cuyo interesante trabajo tiende, como es usual en los agrónomos, a desvalorizar los esfuerzos empíricos anteriores a las hibridaciones científicamente controladas. 
de algún modo, al menos llamar la atención sobre esa brecha en el conocimiento.

\section{EL ÁMBITO Y LA PERIODIZACIÓN}

La región aquí estudiada, que en términos generales se denomina pampa húmeda (una gran planicie de alrededor de $600000 \mathrm{~km}^{2}$, con precipitaciones anuales iguales o superiores a los $600 \mathrm{ml}$, de clima templado y con suelos de pradera mayormente llanos), es a nivel mundial una de las más emblemáticas porciones del planeta aptas en su casi totalidad para el cultivo de cereales en gran escala y en secano; fue puesta en producción de forma irregularmente progresiva, $\mathrm{y}$ por ello, $\mathrm{y}$ por las diversas subregiones que incluye, no es posible brindar un esquema homogéneo de la superficie que abarcó a lo largo del siglo xix. En todo caso, lo importante es remarcar que esa misma dinámica de ocupación progresiva es parte fundamental de la generación de estrategias adaptativas que están en el centro de las innovaciones de la tecnología agraria. Aun dentro de las pautas generales mencionadas, la diversidad edafológica, un heterogéneo balance hídrico, el impacto diferencial de este, tanto en la sustentabilidad de los cultivos como incluso para la mera existencia humana, y los efectos de plagas y fenómenos de estrés ambiental, fueron delimitando condiciones sumamente cambiantes y generando constantes desafíos a la iniciativa de los productores. El hecho de que existiera además durante ese periodo una extensa frontera con etnias indígenas independientes, con lógicas alternas de paz y de guerra, varió en forma permanente la ecuación de rentabilidad, en la que además de los ya mencionados riesgos ambientales era menester tener en cuenta muchos otros. En aras de la brevedad, entonces, sólo diremos que los procesos que estudiaremos fueron en general difundiéndose en tiempos diversos por un área que comprende la mayor parte de las actuales provincias argentinas de Buenos Aires, Santa Fe, Entre Ríos, el sur de Córdoba y 
el noreste del territorio de La Pampa, área en la que, hasta cierto punto, las recetas tecnológicas generales podían tener validez. ${ }^{15}$

Es de mencionar además que la información con la que contamos para ese largo periodo dista mucho de ser completa: faltan estudios de detalle y reportes de casos subregionales. Pero de todos modos nos es posible establecer algunas pautas más o menos firmes, que a su vez nos ayudan a trazar un recorrido diacrónico relativamente sólido y común. Limitándonos, como hemos dicho, a la agricultura del trigo, podemos identificar cuatro claros momentos de transformación: el primero, que abarca desde los años finales del siglo xviII y llega hasta alrededor de 1840, en que la producción se desprende lentamente de las pautas tradicionales e ingresa en la agricultura de fronteras; el segundo, que va desde entonces hasta el afianzamiento de las colonias agrícolas primigenias hacia 1864 , en que esa agricultura de fronteras adquiere entidad fuera de sus núcleos iniciales y se instala como alternativa viable incluso frente a los manchones de cultivo periurbano del interior; el tercero, que va desde 1865 hasta 1878, cuando se define una nueva agricultura extensiva montada sobre procesos de mecanización integrados dinámicamente en los segmentos críticos con mayor inversión de mano de obra y que cubre progresivamente la demanda ampliada de las regiones interiores del país y de sus ciudades principales, preparando el gran dinamismo del periodo siguiente, y este último, que cubre el acceso al mercado mundial y la construcción de una oferta especializada bajo pautas de selectividad propias

15 Aun cuando en parte el actual Uruguay y áreas del sur del Brasil también conforman la pampa húmeda, guardan diversidades regionales propias, muchas de las cuales impactaron en las condiciones del cultivo. Por ello, más que por los límites de los estados nacionales actuales, es que no las incluimos aquí. Una muestra de la diversidad de situaciones aun dentro de la región pampeana húmeda en Argentina. Consejo Federal De Inversiones, Evaluación, t. III y IV (vols. I y III). 
del consumo europeo. Seguidamente analizaremos cada uno de esos momentos.

\section{LOS INICIOS: EL DURO TRABAJO DE DOMINAR UNA NUEVA ECUACIÓN AMBIENTAL, CA. 1800-1840}

El recorrido comienza hacia finales del siglo XVIII, con pequeñas superficies sembrada, y promedios de siembras muy diferentes según la región, pero que oscilaban entre apenas 2 o 3 ha en la provincia de Córdoba, ascendiendo a alrededor de 6 o 7 en el este de Entre Ríos, y llegando a 8 o 10 en las explotaciones más concentradas del norte de Buenos Aires y sur de Santa Fe, la zona más productiva por entonces y que integraba el corredor de abasto de la ciudad principal del territorio. ${ }^{16}$ Esa agricultura tradicional se concentraba sobre todo en las cercanías de pueblos y ciudades, y en las áreas húmedas de las orillas de los ríos; protegida a menudo por barrancas o por bosques artificiales, trabajaba por tanto tierras muy muelles, necesitando sólo arados muy básicos de poco poder de penetración. ${ }^{17} \mathrm{La}$ especialización no era relevante; a menudo se combinaban diversos cultivos en etapas sucesivas y en diminutas parcelas contiguas, sobre todo con el propósito de vender sus productos en el mercado, aunque sin duda parte de la cosecha fuera destinada a autoconsumo. Los problemas mayores eran el precario equilibrio del balance hídrico y la constante amenaza de enfermedades criptogámicas. ${ }^{18}$

\footnotetext{
16 Sobre Entre Ríos, datos de percepción del diezmo de granos en AGN, $D$, sala IX, exp. 20-5-7, leg. 1; resto en Garavaglia, Pastores y labradores, pp. 7-27.

17 Muchos testimonios respecto del supuesto "descuido" con que se realizaba la roturación tradicional en el Río de la Plata; esta actitud era sin embargo adecuada para tierras mullidas y húmedas. Isabelle, Voyage, p. 264. Un ejemplo tardío de la escasa necesidad de roturación en tierras húmedas y mullidas en SASTRE, El Tempe, t. II, pp. 179-180.

18 Grigera, Manual, pp. 7-17, 20, 23-28; Pérez Castellano, Observaciones, pp. 274-295.
} 
Ese patrón productivo comenzó a sufrir cambios con los avances sobre tierras de frontera. Durante las últimas décadas del siglo XviII se logró una relativa paz con las tribus indígenas, que permitió que la población criolla se expandiera. Después de las guerras de independencia, en la década de 1820, la apertura del puerto de Buenos Aires al comercio internacional y una creciente orientación a la producción de ganado para la exportación de cueros y otros subproductos impulsaron los procesos de ocupación de tierras de frontera, surgiendo nuevos poblados en esas áreas..$^{19} \mathrm{Las}$ nuevas poblaciones requirieron crear sus abastos, enfrentándose con condiciones ambientales diferentes a las de las áreas hasta entonces en cultivo. ${ }^{20}$ En ese periodo otra de las muchas novedades fue la aparición, en la franja fronteriza, de grandes productores de trigo, algunos también ganaderos que diversificaban sus inversiones. Para ellos, los mercados locales eran lógicamente poco atractivos; el objetivo mayor era la ciudad de Buenos Aires, cuyo consumo del cereal aumentaba constantemente y no podía ya ser suplido por los productores tradicionales. ${ }^{21}$ En ese contexto se abrieron nuevos nichos de oportunidades mercantiles: el cereal de las fronteras, que usufructuaba los mayores rendimientos propios de las tierras nuevas y economías de escala facilitadas también por un rústico sistema de nuevos puertos, se pudo colocar en la

\footnotetext{
$19 \mathrm{Al}$ respecto véase por ejemplo Banzato, La expansión, o el clásico HalpeRIN DoNGHI, "La expansión ganadera".

20 Ya en 1802 un artículo llamaba la atención al respecto. Cerviño, "Carta", pp. 109-111.

${ }^{21}$ Los costos de la agricultura periurbana habían ido ascendiendo; la gradual extinción de la esclavitud (con la prohibición de introducir esclavos desde el año 1812 y la libertad de vientres instaurada en 1813) dejó a las grandes chacras aledañas a la ciudad sin mano de obra barata, y el incremento del precio de la tierra tornó más rentables otras actividades, como la elaboración de material de construcción y la cría de ovinos en las décadas de 1820 y 1830. Burgin, Aspectos económicos, p. 162.
} 
ciudad de Buenos Aires para abastecer una demanda creciente. ${ }^{22}$ Así, se instaló en esos años en el mercado porteño la distinción entre trigos de costa y trigos salados, estos últimos asíllamados por provenir del área del río Salado, en las nuevas tierras del sur. La competitividad de los trigos de las fronteras (salados) era sin embargo precaria; si los precios del cereal descendían demasiado, sufrían discriminación intensa, debido a la menor calidad del grano y los mayores costos de transporte que debían soportar respecto a los trigos de costa. Pero desde 1820 los precios se sostuvieron en niveles mucho más altos que antaño, y fueron sumamente variables, con episodios de bajas y frecuentes coyunturas críticas en las que se disparaban, marcando la tónica de casi toda la primera mitad del siglo XIx.23

Las técnicas agrícolas acusaron el impacto de las nuevas condiciones. En primer lugar, se ha recabado para esas áreas de frontera evidencia dispersa - pero concluyente- acerca de los efectos de la ampliación de la escala operativa: arados de gran porte, cosechas individuales de más de $100 \mathrm{t}$, áreas de cultivo equivalentes a varias decenas de ha. ${ }^{24}$ Si bien rara vez los inventarios de chacras y estancias detallan exhaustivamente los arados, al menos de manera que nos permita seguir con detalle sus modificaciones, de todos modos es evidente que los mismos

${ }^{22}$ El tráfico por el río Salado redujo los costos de transporte cerealero, más altos que para cueros y ganado. Si bien la fiscalización de esos puntos remotos fue deficiente, existen muchos testimonios de la actividad de los puertos de esa zona durante casi toda la primera mitad del siglo xIX, en particular en épocas de bloqueo del puerto principal, Buenos Aires. Véase Galarza, "Un nuevo puerto", pp. 83-107.

${ }_{23}$ DJendeRedjian, La agricultura pampeana, pp. 149-180.

${ }^{24}$ Registro de un arado pesado con ruedas y tracción equina en 1822, en GaraVaglia, Pastores y labradores, p. 186. En 1820, Jacinto Arauz, labrador de Lobos, efectuaba roturaciones "con peones" en la otra banda del Salado, habiendo cosechado allí el año anterior 1110 fanegas de trigo (la fanega bonaerense tenía 137.2 litros de trigo). AGN, TC, sección letra N, 2, 1815-1821, fs. 1 y 3r. exp. "Noriega Andres con Jacinto Arauz". 
han empezado a transformarse: ya no se trata tan solo de los primitivos instrumentos criollos, hechos apenas con un rústico madero a veces endurecido al fuego; ahora hay partes metálicas, siendo las rejas de hierro las más frecuentes..$^{25}$ Asimismo, se les incorpora un dispositivo para regular la profundidad de labran$\mathrm{za}$, es decir, para subir y bajar a voluntad la reja, mediante una articulación movible entre el timón y el dental, y una clavija para mantener fija la distancia entre ambos durante la labor. Esos detalles no existían en el siglo XviII, según lo muestran la iconografía y descripciones disponibles. ${ }^{26}$ Crece también la oferta de más y mejores instrumentos importados. ${ }^{27}$

Ello lógicamente se expresaba de otras formas: los saberes de la siembra y la cosecha empiezan a ser sistematizados y ordenados; se publican los primeros manuales de agricultura, más metódicos que las antiguas y vagas instrucciones dispersas en la correspondencia, apuntando a racionalizar el uso de recursos escasos y a circular con rapidez la información. ${ }^{28}$ En las zonas de frontera recientemente incorporadas al stock de tierras productivas, y cuyas condiciones ambientales diferían de las usuales en las zonas ocupadas desde antiguo, uno de los mayores problemas de la producción rural se relacionaba con el manejo del

25 Sobre Santa Fe, Bidut, Caula y Liñán, "Productores”; arados americanos modernos en Paraná hacia 1850 en Burmeister, Viaje, t. I, p. 227; el inventario de los bienes de chacra de Tomás González, levantado en 1853 en Gualeguaychú, Entre Ríos, registra "tres arados a veinte reales", una cifra que al menos duplica el valor de cualquier otra herramienta metálica. AIM, fondo general, c. I, carp. 57, doc. 1947, f. 1 v.

${ }^{26}$ Por ejemplo, el arado proyectado por Fernando Ulloa para los campos del Río de la Plata en 1778, reproducido en Álvarez, Ensayo, p. 174, en que el timón aparece fijo en el dental. Comparar con el arado "del país" reproducido en Pellegrini, "Arados".

27 Brown, Historia, pp. 254-255; El Labrador argentino, 1857, t. II, p. 20; la exportación de maquinaria al Río de la Plata alcanzaba varios miles de libras por año en la década de 1820. Custom House, Machinery.

${ }_{28}$ Ejemplos en Rosas, Instrucciones; Grigera, Manual. En la producción ganadera, lógicamente, esa obsesión por las normas es mucho más evidente. 
agua. La zona de las pampas donde se expandía el ganado, es decir, la provincia de Buenos Aires allende el río Salado, es una planicie mucho más llana que al norte de este, donde los cursos de agua escasean, semiesteparia, con especies ralas arbustivas y pastos "duros": el balance hídrico era a menudo deficitario. ${ }^{29}$ Pronto se constató la existencia de aguas subterráneas, pero los aparatos experimentados para extraerla apenas servían para dar de beber a personas y animales. Los cultivos eran y continuarían siendo exclusivamente de secano. ${ }^{30}$ Esas condiciones reducían significativamente el impacto de las enfermedades criptogámicas, pero a la vez era menester precaver los cultivos contra súbitos descensos en las precipitaciones esperadas, algo muy frecuente en las pampas. Aun sin llegar a la sequía (que las hubo, y catastróficas), la fragilidad de los cultivos era así mayor. ${ }^{31} \mathrm{La}$ observación directa, la experimentación y la experiencia práctica fueron impulsando recetas para reducir esos riesgos, que debían tener en cuenta el aumento de la escala de producción.

Este último fenómeno planteó desafíos nuevos en el segmento del laboreo de la tierra previo a la siembra. Tradicionalmente, este se basaba en la realización de amelgas, es decir, montículos paralelos en cuyas cumbres se introduciría la simiente, en

${ }^{29}$ Los pastos "duros" constituyen el tapiz vegetal original pampeano, previo a la expansión de rebaños de ganado vacuno; el pastoreo implica su progresivo reemplazo por los llamados pastos "blandos", por efecto de la selección hecha por los animales al consumirlos y dispersarlos.

30 Halperin Donghi, "La expansión"; Sbarra, Historia; un interesante testimonio en Juan M. de Rosas a Domingo Arévalo, s/l, diciembre de 1826, reproducida en La Agricultura, año IV, 157 (2 ene. 1896), p. 7; también artículos diversos en la prensa, como El Centinela, Buenos Aires, 21 (15 dic. 1822), p. 354, y Los Amigos de la Patria y de la Juventud, Buenos Aires, 3 (15 ene. 1816), pp. 11-12.

${ }^{31}$ Las sequías de la primera mitad del siglo xix fueron particularmente graves entre 1801-1804; 1808-1810 y 1827-1832. Desde 1795 hasta 1842 hubo en la zona pampeana bonaerense 18 años de sequía reportados, o sea, 38\% sobre el total. Deschamps, Otero y Tonni, “Cambio climático”, pp. 13-16. 
general luego de alguna lluvia. ${ }^{32}$ Después, se efectuaban pasadas superficiales con el arado para enterrar la semilla, y gradas para emparejar un tanto la superficie. ${ }^{33}$ La labor en amelgas permitía que el agua se escurriera con facilidad hacia los surcos, evitando acumulaciones perjudiciales de humedad en torno al cultivo. Malezas y criptógamos eran combatidos con drenajes ad hoc, con saturación de semillas y trabajos de carpida manual, o araduras sucesivas en la etapa previa a la siembra. Por ello las amelgas se formaban angostas, con un ancho de 3 o 3.5 metros.

En cambio, en las condiciones del cultivo de fronteras, con superficies más amplias y humedad ambiente menor, esos métodos debieron modificarse. Lo que primero se amplió fue el ancho de las amelgas; Juan Manuel de Rosas pensaba que el mismo debía estar entre 3 y 5 varas, es decir, entre 2.6 y $4.3 \mathrm{~m}$, siendo preferible un ancho mayor "porque el melgador acaba más pronto, y lo mismo el derramador”. ${ }^{34}$ Ello, a la vez que ahorraba mano de obra, permitía que las plantas aprovecharan mejor la más escasa humedad relativa, al encontrarse más separadas unas de otras. Es también probable que a ese afán por asegurar las condiciones de humedad correspondiera el interés

32 Según Müller, Novísimo diccionario, t. I, p. 592, la amelga es una "porción de terreno que el labrador señala en una haza [parcela] para esparcir la simiente con igualdad y proporción; para ello, cuando la tierra está labrada y dispuesta, se trazan con el arado unos surcos paralelos [...]". En la actualidad han dejado de emplearse, en especial luego del desarrollo de la siembra directa a partir de la década de 1980.

33 Esas labores rudimentarias eran suficientes en ámbitos húmedos. PÉrEZ Castellano, Observaciones, p. 283.

34 Rosas, Instrucciones, p. 37. Juan Manuel de Rosas, gobernador de Buenos Aires en dos periodos (1829-1832; 1835-1852) fue el político más importante de la primera mitad del siglo xix argentino y uno de los más grandes productores rurales de su época. Se conservan de su mano instrucciones para el manejo de estancias y chacras. Una exhaustiva biografía reciente en FradKIN y Gelman, Rosas. 
por trabajar la tierra con arados de penetración más profunda. ${ }^{35}$ Con el tiempo, esas modificaciones darían lugar al desarrollo de la labor en tablones (como veremos más adelante, en la figura 2), variante de la tradicional labranza en amelgas, que luego de ampliar la distancia entre los surcos derivó en la interposición de uno doble entre aquellas. ${ }^{36}$

Pero de todos modos la construcción de las técnicas más adecuadas para la labor en tierras nuevas habría de demorarse. Resuelto hacia diciembre de 1826 el problema principal de la obtención de agua con el nuevo sistema del balde volcador, ${ }^{37}$ los esfuerzos se orientaron principalmente hacia el ahorro de mano de obra, crucial por el constante conflicto entre los productores rurales y los ejércitos que buscaban reclutas. Surgieron así técnicas de reorganización, como el reemplazo de contratos de trabajo "por día" por otros por "tareas". ${ }^{38}$ Aun sin entrar en detalle, estos y otros cambios aparentemente menores están muy en línea con el concepto de "innovaciones incrementales"

\footnotetext{
${ }^{35}$ Las Instrucciones de Rosas parecen en ello seguir a SINCLAIR, L'Agriculture, t. II, pp. 7-15.

36 Daireaux, Manual, pp. 143-148. No está claro cuándo se modificó la tradicional labranza en amelgas para transformarla en labor en tablones; ese tipo de labor era más adecuado en tierras con cierto grado de humedad, ya que permitía un buen manejo del desagüe, pero no en las demasiado muelles y húmedas, como las de las orillas de los ríos, donde las labores buscaban sobre todo administrar esa humedad excesiva.

37 Se trataba de un sistema simple para extraer agua de pozos. Al respecto puede verse SBarra, Historia, pp. 15-37.

38 Preferidos estos últimos en las zonas de frontera, pero también presentes en las de antigua ocupación. Rosas, Instrucciones, p. 59. La "tarea" se definía en torno a unidades de superficie de 35 varas de largo por 15 de ancho. En las cuentas de gastos de un labrador de San Isidro, en el norte bonaerense, se registró el pago de 42 tareas a 28 pesos moneda corriente; el jornal de un peón era en esos días de 30 pesos. AHMSI, DMP, c. 1, Agricultura, "Cuenta de los gastos que se han echo...", firmada por Andrés Sorondo.
} 
de Kauffman..$^{39}$ Las transformaciones de esos años no formaron así parte de un conjunto orgánico, entre otras cosas porque faltaban aún elementos fundamentales para ello: nodos de innovación e intermediarios, es decir, medios de comunicación entre los mismos, que permitieran un ataque radical a las pautas de producción existentes mediante el uso combinado de técnicas, maquinaria y experimentación de procesos nuevos. Sin embargo, esas pequeñas modificaciones y estrategias adaptativas constituirían una base lo suficientemente sólida para la generación de una tecnología agrícola de nuevo cuño en la etapa siguiente.

\section{LA EXPANSIÓN DE LA AGRICULTURA DE FRONTERAS}

Y EL SURGIMIENTO DE NODOS DE INNOVACIÓN, 1840-1864

La coyuntura 1838-1839, con sequía, fuertes procesos inflacionarios y conflictividad social y bélica, inaugura en el Río de la Plata un ciclo de muy altos precios del trigo; la década siguiente, conocida como los hungry forties, verá exacerbarse esa tendencia ya no sólo por factores locales. ${ }^{40}$ Los precios del trigo se sextuplican entre 1835 y 1843 y, lo que es más importante, durante toda la década de 1840 sus niveles mínimos se mantendrán entre el doble y el triple de los del año base, $1835 .{ }^{41}$ Si bien, gracias al bajo valor relativo de la carne vacuna, no se llegó nunca a la hambruna, de todos modos el impacto de esos

39 Kauffman, Investigations, pp. 49-60. El concepto remite a la existencia de cambios aparentemente de menor cuantía (por ejemplo, una modificación de un paso determinado en un proceso de trabajo ya dado) que, sin embargo, al encadenarse unos a otros, y provocar a su vez otras modificaciones de envergadura creciente, terminan por transformar todo el proceso y crear un producto nuevo.

40 Sobre esos años de crisis en Europa, véase Vanhaute, Paping y Ó Gráda, “The European subsistence crisis of 1845-1850", pp. 3-17.

${ }^{41}$ DJenderedjian, La agricultura pampeana, p. 173. 
Figura 1

AVANCE DE LA FRONTERA EN EL ÁREA PAMPEANA, 1810-1877

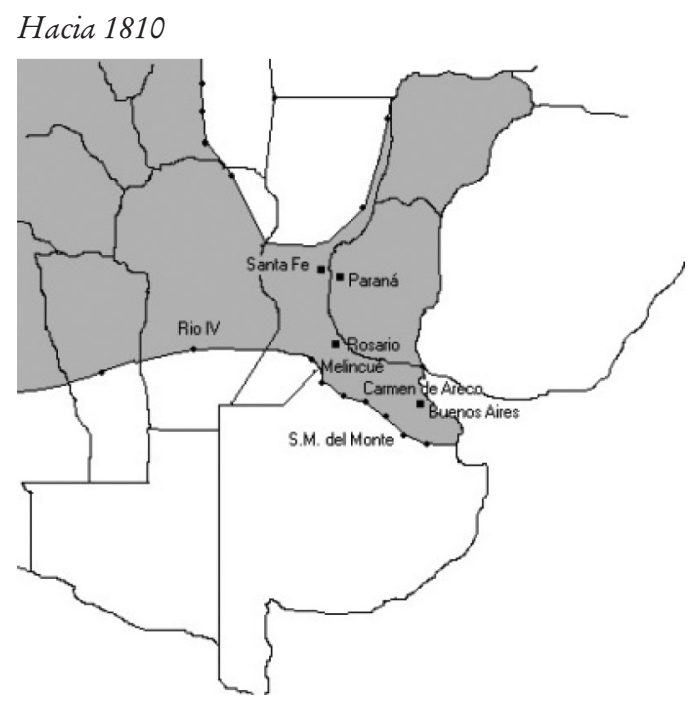

Hacia 1852

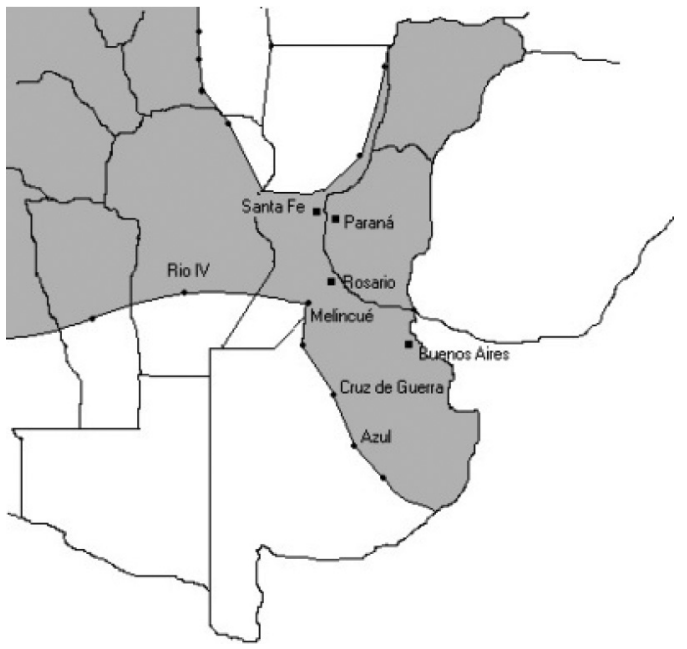

Tomado de BARsky y DJENderedjIAn, La expansión, pp. 100-101. 
Figura 1 (concluye)

AVANCE DE LA FRONTERA EN EL ÁREA PAMPEANA, 1810-1877

\section{Hacia 1864}

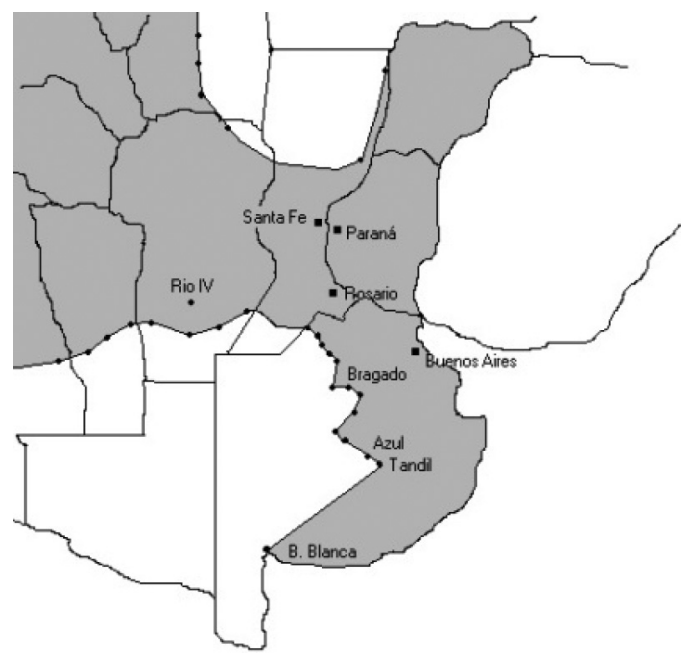

Hacia 1876-1877

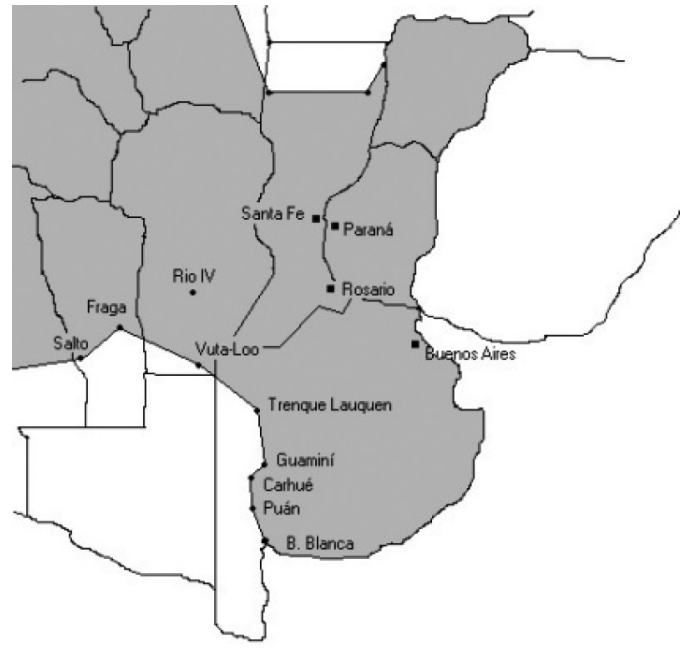

Tomado de Barsky y Djenderedjian, La expansión, pp. 100-101. 
altos precios de los granos habrá de ser grande puesto que buena parte del consumo de harinas procedía de importaciones. Una de las consecuencias fue que, por primera vez, los proyectos de colonización agrícola con extranjeros -ya propuestos desde la década de 1820- comenzaron a ser vistos como una solución posible para el poblamiento y el abasto regular de alimentos. Las colonias fueron concebidas por las élites de las provincias como núcleos estratégicos y defensivos: debían situarse en la zona de frontera con los territorios en manos de indígenas o en los límites con otras provincias. Se esperaba que tuvieran una función militar y no sólo productiva; sus pobladores, afincados localmente, no descuidarían los cultivos como ocurría con los criollos, obligados a servir a menudo lejos de sus parcelas. Esos proyectos se conectaban así con otros que habían sido planeados y aun llevados a cabo en la época borbónica. ${ }^{42}$ La seguridad alimentaria se transformaba en un punto crucial, en medio del incremento constante de los precios de los cereales y sus subproductos, y de la inestabilidad de la oferta importada por los bloqueos de las potencias al puerto de Buenos Aires, consecuencia de las guerras de esos años. No es, entonces, extraño que durante casi toda la década de 1840 se debatieran proyectos de colonización en las distintas provincias, que comenzarían a concretarse en la siguiente. ${ }^{43}$

Pero la nueva colonización desbordó los planes y proyectos de las élites: las colonias se constituyeron en nodos de innovación, es decir, en componentes fundamentales de la construcción de un nuevo paradigma tecnoeconómico en la agricultura

\footnotetext{
42 Sobre el tema véase DJenderedjian, "Roots of Revolution”, pp. 639-668; hay multitud de testimonios de época, por ejemplo, P. A. García, "Diario de un viaje".

${ }^{43}$ La década de 1820 había visto varios proyectos concretados, pero que finalmente fracasaron. DJENDEREDJIAN, La agricultura pampeana, pp. 216-231 y 239-243.
} 
rioplatense. ${ }^{44}$ Aunque esos nodos no fueron los primeros en surgir, sí tuvieron un papel central en la incorporación de áreas nuevas del interior del país al proceso de innovación agrícola, que hasta entonces había estado centrado sobre todo en los campos de Buenos Aires. Allí, a los rústicos ensayos anteriores, se sumó en la década de 1840 el de Chivilcoy, un núcleo de alta productividad agrícola relativa que en esos años se posicionó con éxito como proveedor del mercado triguero porteño. ${ }^{45}$ Desde entonces, a ese y a otros nodos de innovación se sumaron las primeras colonias agrícolas que lograron funcionar: Esperanza, San Carlos y San Gerónimo en Santa Fe, y San José en Entre Ríos. San Carlos, en particular, se posicionó muy pronto como líder regional; fundada en 1858, contaba desde entonces con la más avanzada quinta agronómica experimental. ${ }^{46}$

En esa particular coyuntura, la robustez de precios y demanda estimuló el interés por la actividad agrícola, y resolvió, o al menos mitigó temporalmente, la sempiterna escasez de capital para inversiones en el campo, que fluía sobre todo hacia la ganadería. ${ }^{47}$ Pero es de destacar que el accionar de estos nodos de

\footnotetext{
${ }^{44}$ Por paradigma tecnoeconómico en la agricultura entendemos aquí un conjunto de principios organizativos y técnicos capaces de renovar radicalmente los procesos productivos de todo el sector, que se ponen en marcha a partir de un complejo encadenamiento de modificaciones en la cadena hasta transformarla de forma completa. Para una definición de paradigma tecnoeconómico véase Pérez, "Structural change", pp. 357-375.

45 Sobre Chivilcoy, Andreucci, Labradores. Indicios de cambios en la agricultura bonaerense de mediados del siglo, por ejemplo en MARMIER, Lettres, t. II, pp. 252-254; también JoHnson, A Long Vacation, p. 31 y, aunque no hace justicia a la dimensión de esos cambios, MarTIN De Moussy, Description, t. I, pp. 472-479.

${ }^{46}$ También en San José (fundada en 1857) hubo una quinta agronómica. Las mismas constituían centros de experimentación de cultivos y técnicas agrícolas, sumamente avanzados para la época. No hay estudios recientes sobre esas quintas; un relato desactualizado en Gschwind, Historia.

47 En esos años los precios de los cueros, principal producto de exportación, descienden; la lana, por el contrario, ofrece mayores oportunidades, pero sólo
} 
innovación y la dinámica de la experimentación que en ellos se realizaba continuó y se aceleró aún después de ese ciclo de altos precios. Varias circunstancias se coligaron para ello: la incipiente conexión ferroviaria, que redujo costos, y la consolidación y el desarrollo de nuevos mercados en las colonias. Pero lo fundamental es que la constitución misma de redes que vincularan los diversos nodos de innovación, con sus mediadores, había alcanzado, para mediados del siglo xIx, una dinámica propia lo suficientemente sólida. La construcción de ese nuevo paradigma comenzó así un proceso de creciente diferenciación en contraste con la trayectoria que tendrían las colonias agrícolas de los países vecinos, como Brasil y Chile. ${ }^{48}$

Todo este movimiento siguió teniendo un marcado carácter empírico de ensayo y error, aun a pesar de la existencia de registros de sus procesos. Sin estudios serios de suelos, sin datos continuos del régimen de lluvias, sin análisis sobre el impacto diferencial de las malezas, las plagas o los insectos, cultivar en esas áreas nuevas constituía una apuesta extremadamente arriesgada. ${ }^{49}$ Las estrategias para suplir la falta de esos conocimientos básicos para la toma de decisiones incluyeron el reconocimiento

desde 1857 iniciará un ascenso vertiginoso. Por tanto, en la década de 1840 e inicios de la siguiente, las perspectivas de realización mercantil de la agricultura eran muy convenientes en términos relativos.

${ }^{48}$ Mientras las colonias en Brasil y Chile, aun cuando bastante exitosas, continuaron replicando los patrones productivos y organizativos de la etapa fundacional y no se expandieron demasiado fuera de sus áreas nucleares, las colonias argentinas se extendieron pronto hacia el oeste y el sur, cambiando su diseño para adaptarlo a las nuevas condiciones, y orientándose a la producción especializada y extensiva. En ese devenir se fueron creando nuevos nodos de innovación, por ejemplo en Candelaria, colonia fundada en 1870, o el establecimiento La Germania. Indicios al respecto en Nicolorich, "La Candelaria"; Zeballos, Descripción amena, o Lonfat, Les colonies agricoles, pp. 82-83. Las descripciones de La Germania son bastante abundantes; véase para un momento posterior Holdich, The Countries, pp. 126 y ss.

49 A tal punto llegaba la ignorancia que aun en 1876 los expertos más importantes debatían si las pampas eran o no lo suficientemente fértiles para el 
topográfico del área por parte de expediciones exploratorias, y la adaptación o incluso el desarrollo de procesos de trabajo específicos, según las condiciones ambientales del área en cuestión. ${ }^{50}$ Téngase en cuenta que el paso de una laxa ganadería extensiva a parcelas de cultivo significó el surgimiento de nuevas comunidades rurales de varios cientos o incluso miles de habitantes en pocos años. $\mathrm{Al}$ mismo tiempo, impuso nuevas necesidades: debía asegurarse previamente la existencia de insumos básicos como el agua, y prever distintas etapas de roturación, las primeras más intensas a fin de romper los terrones apelmazados por el constante paso de animales, y las subsiguientes para erradicar plantas adventicias.

A ello se sumó la emergencia de intermediarios, es decir, instancias de intercambio de experiencias y discusión de resultados entre los diversos actores involucrados, ya fueran estos productores, proveedores de maquinaria, funcionarios, clientes del producto final o los primeros agrónomos. Fueron de carácter público y privado; entre los primeros, mencionaremos aquí sobre todo dos: ferias y exposiciones, y publicaciones periódicas. Supliendo la absoluta falta de organismos técnicos estatales encargados de recopilar información, esas redes y esos intermediarios se convirtieron en elementos fundamentales del proceso de innovación. Las ferias comienzan también a constituirse en ámbitos de presentación y apreciación de productos, así como de contacto entre proveedores y clientes, toda vez que coincidían allí productores rurales, proveedores de maquinarias e insumos,

cultivo del trigo. NAPp, La República, pp. 287-288; BurmeIsTer, Description, t. I, p. 364.

${ }^{50}$ El empresario colonizador Guillermo Lehmann, por ejemplo, habría de organizar expediciones exploratorias por las tierras de frontera registrando los cambios de temperatura, las lluvias y los efectos de sequías e inundaciones, y experimentando con los métodos de cultivo más adecuados. BIANCHI DE Terragni, Historia, pp. 173-181; también ImHoff, San Guillermo, p. 145. 
y comercializadores. ${ }^{51}$ Fueron fundamentales también por su papel de campos de experimentación, en particular en pruebas de maquinaria agrícola. El rendimiento de una máquina o de un arado no eran iguales en los distintos tipos de suelo, y por tanto la utilidad de esas pruebas era limitada; pero lo más provechoso era la confrontación de distintos modelos en situaciones de estrés (por ejemplo, en tierras de particular dureza o con presencia de piedras), que, aunque artificiales, de todos modos, exhibían las potencialidades y los límites de cada aparato. ${ }^{52}$

Al lado de los procesos descritos, a partir de la década de 1850, dentro del área del antiguo virreinato del Río de la Plata se ampliaron progresivamente tanto la variedad como el radio de circulación de publicaciones especializadas (folletos, informes, periódicos, libros, revistas), segmentando de esa forma el intercambio de información e independizándolo de la prensa política y los grandes periódicos de las ciudades, en particular los de Buenos Aires, Córdoba y Santa Fe, donde el espacio para discusiones específicas sobre temas agronómicos era acotado. Esos periódicos y folletos difundían novedades técnicas y métodos ensayados localmente o en otros países, discutían sus resultados y publicaban información estadística, precios, y estudios agronómicos, edafológicos y climatológicos. ${ }^{53}$ Esa información fue definiendo

${ }^{51}$ Un aporte reciente al respecto en Di Lisia y LLUCH (comps.), Argentina en exposición. Las ferias regulares comenzaron en 1854.

${ }^{52}$ Fue emblemático al respecto el ensayo de maquinaria agrícola realizado en el marco de la exposición de Córdoba en 1871, cuyos resultados fueron publicados en un libro voluminoso y de mucho impacto. Costa, Informe del Comisionado.

${ }^{53}$ No hay, que sepamos, un análisis integral de las publicaciones agrarias de la época; pero el conjunto creció con rapidez. Uno de los periódicos especializados más antiguos fue El Labrador Argentino (1856-1857), precedido por varias otras publicaciones esporádicas, que a pesar de no especializarse en el tema agrario le dedicaron mucho espacio, como por ejemplo la Revista del Plata. Desde 1866 se edita en Buenos Aires el periódico Anales, por parte de la Sociedad Rural Argentina, que se transformaría de inmediato en la publicación más avanzada en temas agrarios. 
así las peculiaridades de la agricultura pampeana, y demostrando la futilidad de la transposición simple de procesos e instrumentos pensados y elaborados para otras realidades agrarias, lo cual tuvo mucha importancia en el desarrollo de un paradigma de técnicas de cultivo específicas. ${ }^{54}$ Además, en esta época temprana la circulación de información era a menudo oral, y la adaptación dinámica de procesos, instrumentos y manuales traídos de Europa o Estados Unidos se hizo sobre la marcha. Por tratarse sobre todo de una serie de saberes repetitivos, su aprendizaje era rápido; la optimización e introducción de mejoras podía también llevarse a cabo a nivel individual, porque era usual que cada productor conociera y dominara todas las etapas o segmentos del proceso productivo, que no poseía aún excesivas complejidades.

Ya desde la década de 1860, quienes acumularon y redistribuyeron información fueron sobre todo las administraciones de las colonias, que concentraron know how por sus facultades de control de la producción y su domino de la quinta agronómica, clave por su papel como centro de experimentación de nuevas técnicas de cultivo en distintos ambientes. ${ }^{55}$ No todas las administraciones o los administradores se comprometieron con el adelanto de las prácticas, ni tuvieron condiciones óptimas para detectar, implementar y difundir mejoras del proceso productivo, o encontrar soluciones a los múltiples problemas que se presentaban; pero, estando siempre estrechamente unida la suerte de las empresas y las colonias a la de los mismos colonos, la sinergia positiva entre todos esos actores era crucial en su éxito. ${ }^{56}$

${ }^{54}$ Esa presunción se ve reflejada por ejemplo en el proyecto de colonia elaborado por BRougnes, Extinction du paupérisme, pp. 62-63. Los informes periódicos de la evolución de las colonias, iniciados en 1864, fueron una fuente clave.

${ }^{55}$ Sobre las quintas agronómicas, véase la nota 46.

${ }^{56} \mathrm{Al}$ respecto Gallo, La pampa, pp. 74-76. En cambio, en las colonias brasileñas, al menos, el papel del administrador no parece haber sido significativo en lo que respecta al cambio técnico. SEYFerTh, A colonização, p. 103. 
Uno de los hechos significativos de la extensión de la agricultura de fronteras durante este periodo es la aparición de nuevas variedades de trigo, necesarias para las condiciones ambientales en las que debía desenvolverse. Durante la primera mitad del siglo xix hubo varios intentos fallidos, siempre en forma empírica y mediante ensayo y error. Sin embargo, se logró finalmente un hito perdurable con el trigo Barletta, que tendrá un desarrollo realmente espectacular en estos años, transformándose, a inicios del siglo $\mathrm{xx}$, en la semilla líder de la agricultura triguera pampeana, presente en cultivos desde el grado 33 hasta el 45 de latitud sur, es decir, de un extremo a otro del área cerealera. ${ }^{57}$ Los prototipos fueron traídos de Italia en 1844 por un comerciante genovés, que inició siembras experimentales en una chacra de su propiedad, instruyendo asimismo a otros agricultores en el manejo de la nueva variedad, con inmenso y rápido éxito, a juzgar por el ritmo de su difusión. ${ }^{58}$

El trigo Barletta constituye una variedad del turgidum, es decir, es de caña llena y grano regordete; posee aristas, y hubo de evolucionar desde alguno de los trigos rústicos y productivos, aunque no de harina de máxima calidad, que se cultivaban en Europa meridional en la primera mitad del siglo XIx..$^{59} \mathrm{La}$ evolución local de la variedad no consta en registros escritos, pero hay evidencia de que no hubo control formal alguno en su rápida expansión. A fines del siglo XIX existín distintos trigos

\footnotetext{
${ }^{57}$ Algunos testimonios respecto del Barletta: RUTTER, Wheat-growing, pp. 90-92; Daireaux, Manual; Simois, El trigo, p. 13.

58 Petriella y Sosa Miatello, Diccionario, entrada “Caprile, Jacinto". Los italianos, y particularmente los sardos, eran actores importantes de la economía rioplatense en la primera mitad del siglo xIx. El carácter masivamente oral de la transmisión de información en esos años, y la falta de registro de los hitos fundamentales del proceso de innovación, resulta patente en el hecho de que sólo 30 años después de la introducción del Barletta existiera ya bastante confusión respecto de su origen. Véase Anales de Agricultura, t. II: 4, Buenos Aires (15 mar. 1874), p. 53.

59 Aragó, El trigo, t. I, pp. 107 y ss.
} 
duros más o menos rojizos, muy rústicos, todos con aristas, a los cuales se daba el mismo nombre, lo que podría apuntar a la existencia de desarrollos paralelos desde diferentes tipos originarios, o a sucesivas difusiones a partir de una misma semilla, o a simple confusión de denominaciones. ${ }^{60}$

Lo realmente notable es que el Barletta resolvió varios de los problemas que planteaba la expansión del trigo hacia las tierras nuevas: constituía una semilla de muy alta calidad adaptable perfectamente a las condiciones del cultivo extensivo en secano (similar al Turkey Red de Kansas), resistiendo el desgrane aun bajo vientos intensos. ${ }^{61}$ Las espigas compactas y de aristas fuertes del Barletta se mantenían mejor cohesionadas que las de cualquier otra variedad, pudiendo permanecer así incluso bastante tiempo después de madurar, lo que constituía una ventaja inapreciable en momentos en que resultaba difícil obtener y coordinar la mano de obra suficiente para la cosecha. Además, el Barletta resistía mejor las distintas condiciones ambientales. ${ }^{62}$ Todavía a inicios del siglo xx continuaba siendo el preferido a causa de su resistencia y adaptabilidad, habiendo sido uno de los instrumentos fundamentales de la fenomenal expansión agrícola pampeana. ${ }^{63}$

60 Simois, El trigo, p. 13. Para inicios de la década de 1850 el Barletta ya constituía uno de los trigos más cultivados en Buenos Aires. Bernardo Gutiérrez al Juez de Paz, Mercedes, 30 de junio de 1856, en Registro Estadístico del Estado de Buenos Aires (2do. semestre de 1855), 7 y 8, pp. 35 y ss. También GaravaGLIA, Pastores y labradores, p. 191.

${ }^{61}$ Los aún altos tallos y la carencia de árboles hacían muy difícil evitar grandes pérdidas de grano en los cultivos extensivos de las pampas; ninguna de las habituales recetas de la protegida y costera agricultura tradicional podía funcionar allí. Napp, La República; El Labrador Argentino, Buenos Aires, t. I, 1856, p. 56; Garavaglia, Pastores y labradores, p. 193.

62 RutTer, Wheat-growing, pp. 91-93; Daireaux, Manual, pp. 430-431; SIMOIs, El trigo; ScobIE, Revolución, p. 112.

${ }^{63}$ Se comparaba de manera favorable incluso con otras variedades que daban mejor harina, por su resistencia a las difíciles condiciones de cultivo en las pampas. Manuel Villarino a Gervasio de Posadas, Chivilcoy, 28 de abril de 
Donde no se logró aún, sin embargo, una solución integral, fue en el ámbito de los instrumentos de labranza. Hemos ya mencionado que la expansión de los cereales por las tierras fronterizas implicó un aumento en las superficies promedio cultivadas por unidad productiva. Con ello, la tendencia hacia el ahorro de mano de obra se hizo más acuciante, a la vez que era necesario obtener mejores resultados de las labranzas efectuadas. La experimentación en torno a este segmento buscó reducir el número de araduras, a fin de preparar más terreno con menos gasto en trabajo; pero ello obligaba a lograr labranzas aún más profundas, a fin de remover mejor el suelo y permitir, mediante el uso posterior de la rastra (o grada), que aquel quedara eficazmente preparado para recibir la semilla. Por tanto, los arados debían ser sólidos, con partes metálicas de fácil recambio y, sobre todo, lo suficientemente livianos como para poder ser arrastrados por los animales de baja capacidad de tracción disponibles en las pampas. ${ }^{64}$ Pero a la vez, debían penetrar profundamente en la tierra, que, en caso de roturación de suelos vírgenes, era muy dura y resistente. ${ }^{65}$

1859, en Estado de Buenos Aires, Exposición agrícola, pp. 23 y ss. Para la segunda década del siglo xx, si bien continuaba siendo "lo más apreciado en nuestro mercado", un experto recomendaba alternarlo con otras variedades para reducir los riesgos de adaptación a los ya muy distintos ambientes de cultivo, y el impacto climático consiguiente. CAMPolieti, La ciencia, pp. 92-93. ${ }^{64}$ Ya se tratase de bueyes o de caballos, en particular estos últimos dejaban mucho que desear al respecto, puesto que tradicionalmente solo se los criaba para silla o para competencias hípicas. El desarrollo de planteles de caballos de tiro implicaba un cambio genético imposible de encarar en poco tiempo, y por lo demás costosísimo; y resultaban más difíciles de amansar que los bueyes, y de costo de mantenimiento mayor.

${ }^{65}$ Lemée, Tratado, pp. 53-54; Costa, Informe, pp. 109-110. El debate sobre el uso de bueyes o caballos para la tracción fue intenso durante toda la época; aún en 1893 un agricultor anónimo defendía el uso de bueyes por su menor costo, en particular para las explotaciones pequeñas. "Un agricultor. Carta al Director de El Campo y el Sport", Pilar, 28 de abril de 1893. En El Campo y el Sport, t. I, nº 68, Buenos Aires (6 mayo 1893), p. 871. En los últimos años se 
Desde los primeros ensayos se fueron descartando ciertas variedades de arados demasiado livianos, poco eficaces para la labranza en tierras vírgenes, aunque exigían menor poder de tracción. Los arados europeos, de hierro batido, más resistentes y pesados, pero a la vez más caros, se contraponían a los modelos estadounidenses, de hierro fundido y así más baratos, aunque más propensos a romperse. En la década de 1860 los estadounidenses parecían ganar la partida; pero servían mejor para trabajar terrenos ya labrados, no para desmontar por primera vez la tierra, porque no penetraban lo bastante en el suelo endurecido. ${ }^{66}$ Ello favorecía la vigencia de los arados simples perfeccionados utilizados en el país, con los que de todos modos era preciso repetir la roturación por lo menos seis veces. ${ }^{67}$ El principal problema de estos arados metálicos no era tanto el costo de las frecuentes reparaciones, sino los imprevistos tiempos muertos que implicaban en medio de la labor, en tanto en las soledades pampeanas de las décadas de 1850 a 1870 resultaba extremadamente dificultoso encontrar un herrero práctico disponible. ${ }^{68}$ La solución, provisoria, radicó entonces en la incorporación de rejas metálicas intercambiables a los arados de madera tradicionales; todavía en la década de 1860 era frecuente utilizarlos, a la par de otros arados de mayor sofisticación. ${ }^{69}$ Pero será en el periodo siguiente cuando surgirán alternativas

ha revalorizado el papel histórico de los bueyes de labor agrícola incluso en Gran Bretaña, donde se suponía que habían desaparecido antes de mediados del siglo xix. Collins, "The latter-day history”, pp. 191-216.

66 Brown, Historia, pp. 254-255; Martin de Moussy, Description, t. I, p. 479.

${ }^{67}$ Burmeister, Viaje, t. I, p. 470.

${ }^{68}$ Carlos Lemée relataba en 1871 el caso de un agricultor bonaerense que había empezado ese año sus trabajos de labranza con 13 arados estadounidenses; al concluirlos sólo le restaban 5, habiendo utilizado bueyes mansos y peones aptos, e incluso gastando 300 pesos en composturas de rejas de acero y 125 en rejas nuevas. El monitor de la campaña, Exaltación de la Cruz (27 nov. 1871), 23 , p. 1.

69 Pellegrini, “Arados”. 
capaces de resolver definitivamente ese problema, como veremos pronto.

\section{LA CONSTRUCCIÓN DE UNA AGRICULTURA} ESPECIALIZADA, 1865-1878

La Guerra del Paraguay (1865-1870) abrió súbitamente una fuerte demanda de granos para alimentación de los soldados combatientes; esa demanda se concentró particularmente en el noreste del país, es decir, muy cerca de la zona de las colonias de Santa Fe y Entre Ríos, generando por tanto un incentivo muy fuerte a la especialización cerealera. ${ }^{70}$ En los centros agrícolas técnicamente más avanzados, resuelto el mayor problema del cultivo (la semilla), se encaró finalmente la tarea de lograr mejores instrumentos y formas de labranza.

Hemos aludido antes al laboreo en amelgas, que fue adaptándose a las condiciones del medio. Al extenderse las siembras en las tierras más secas del oeste, en los límites de la frontera agrícola, las amelgas se hicieron más anchas, y surgió la labor en tablones, con un surco intermedio adicional. Pero la multiplicación de surcos tornó muy poco práctico este método en superficies aún más extensas: se retrasaba la siembra, y se dificultaba el trabajo de arados modernos, gradas y desterronadoras. Por otra parte, al descender el nivel de humedad ambiente y aumentar el impacto desecante de los vientos, la previsión ligada al escurrimiento de aguas se volvía no sólo innecesaria, sino aun perjudicial. Se imponían entonces soluciones radicales, adoptadas durante el periodo que tratamos aquí: la principal de ellas, la labor en llano, consistía en trazar un solo surco y volver sobre él, volcando la tierra del mismo lado (véase la figura 2). Era un método muy conveniente para las tierras secas, deshaciéndolas mejor que los otros; era además más rápido, porque el conductor del arado no

70 Sobre el tema véase Martirén, La transformación farmer, p. 69. 
tenía más que volver sobre sí mismo para recomenzar la labor. E incluso hacia el final de la centuria aparecieron arados especializados de dos orejas, dobles o mellizos, que realizaban con mayor comodidad el trabajo en llano. ${ }^{71}$

Figura 2

LABOR EN LLANO Y LABOR EN TABLONES

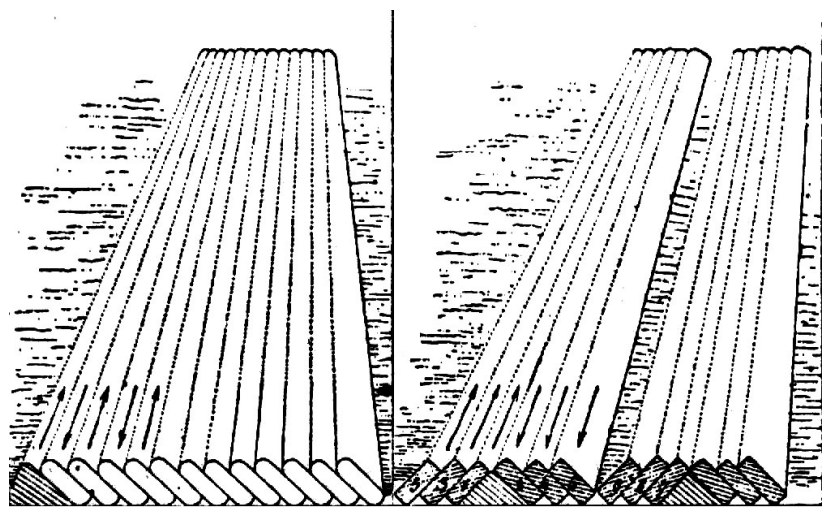

Fuente: Daireaux, Manual, p. 146.

Así, tuvo que modificarse sustancialmente la práctica concreta del arado. Las duras tierras vírgenes de las fronteras exigían un trabajo más intenso, y a la vez acciones conservacionistas de la humedad, con labores más profundas y más rápidas. El problema no se podía resolver como hasta entonces: los arados importados no resultaban prácticos; los criollos, aun con las modificaciones introducidas, no eran aptos para realizar, con eficiencia y rapidez, la labor de roturación necesaria. Ambos tipos de instrumentos, por lo demás, estaban calculados para

${ }^{71}$ A la inversa, la labor en tablones exigía varias pasadas paralelas y luego de las mismas se volvía. Una útil descripción de ambos métodos en DAIREAUX, Manual, pp. 146-148. 
prestar servicios en superficies de cultivo de dimensión acotada, y no para las cada vez más amplias áreas de siembra que surgían al desarrollarse el cultivo especializado. ${ }^{72}$

Las colonias constituyeron así un eficaz laboratorio experimental de nuevas técnicas de labranza. Ya en 1864 se intentó utilizar arados de subsuelo a fin de remover las capas de tierra integrando el loam existente debajo de la superficie de humus. ${ }^{73}$ Pero el impacto de las sequías puede estar indicando que en algunos casos esas labores eran todavía demasiado superficiales para lograr resultados sustentables. ${ }^{74}$ La clave residía en la construcción de prototipos de arado concebidos específicamente para las condiciones locales. Hacia mediados de la década de 1860 se habían logrado ya avances sustantivos: el arado más práctico y difundido entonces era de doble mancera, con control de profundidad y dispositivo para tiro indirecto, lo que aumentaba la eficacia de la fuerza de tracción disponible sin sobreexigir a los animales. ${ }^{75}$ Este arado, fabricado localmente, aún se usaba a finales del siglo XIX, aunque sólo en las colonias antiguas y en chacras pequeñas. ${ }^{76}$ Similar fue el arado especialmente diseñado para los campos santafesinos que llevó a la fortuna a su fabricante, un colono de Esperanza; según Wilcken, hacia 1871 se

72 Los arados criollos modificados de la década de 1860 eran útiles para tierras vírgenes, pero había que repetir las roturaciones al menos seis veces, y no resultaban prácticos en superficies de labranza mayores a las 4 o 5 ha. BuRMeister, Viaje, t. I, p. 470. Daireaux, Manual, p. 143, 141-145. Véase también el importante testimonio de los colonos italianos de Marcos Juárez, Córdoba, en Troisi, L'Argentina, p. 186. Para Beck Bernard, el costo de la primera roturación en tierras nuevas era casi el doble que en tierras ya labradas. BECK Bernard, La République Argentine, p. 263, y pp. 252-262.

73 Perkins, Las colonias, p. 26.

74 Quejas por los fuertes efectos de las sequías todavía a inicios de la década de 1860, en AGPS, G, vol. 22, sin foliar, comunicaciones del Juez de Paz de Esperanza, por ejemplo, al ministro de Gobierno del 13 de noviembre de 1862.

75 Se conservan algunos ejemplares en el Museo de la Colonización de Esperanza; véanse Grenon, La ciudad; Oggier y Jullier, Historia, t. I, p. 142.

76 Miatello, Investigación, pp. 481-484. 
había impuesto como el más adecuado por su solidez, aunque superaba en precio a los arados estadounidenses. ${ }^{77}$

A medida que las superficies a cultivar se ampliaban, los arados de mancera pronto se volvieron insuficientes. El esfuerzo necesario para la conducción, ejercido por el labrador, y el de recomenzarla al terminar el surco, resultaban muy duros y engorrosos en superficies de labranza mayores a las tradicionales concesiones de 33 ha. Se experimentó con varios tipos de arados alternativos, pero la solución llegó con los sistemas de rejas múltiples operadas por palanca. ${ }^{78}$ Estos permitieron desarrollar el arado de asiento, que resolvió eficazmente los problemas antes mencionados y resultaba mucho más cómodo de manejar, pudiendo alzar y rotarse los cuerpos en las cabeceras mediante un simple mecanismo. Estos arados pronto se hicieron populares en las zonas de nueva ocupación, en especial cuando la intensa competencia entre fabricantes locales y extranjeros hizo descender sustancialmente su precio. ${ }^{79}$

Para mediados de la década de 1880 ya se habían integrado a los modelos de arados implementos nuevos para darles mayor eficiencia; por ejemplo, una rueda de control por delante de la vertedera, que rodaba en un plano algo inferior al que seguía la reja en la labor y otorgaba de esa forma más estabilidad a la labranza, anulando las resistencias del terreno y disminuyendo la fuerza de tiro. ${ }^{80}$ Pero todo ello requería mayor tracción: los modelos disponibles trabajaban con cuatro o cinco caballos,

\footnotetext{
77 WiLCKen, Las colonias, pp. 13-17.

${ }^{78}$ Uno de esos sistemas alternativos fue el arado Garabato, Anales de Agricultura, 2 (15 ene. 1873), pp. 12-13.

79 Se desarrolló una fuerte industria local de maquinaria; el establecimiento de Schneider había producido hacia 1900 más de 30000 arados dobles; Tabernig, Kalbermatten y otros industriales lograron premios, renombre y fortuna. Grenon, La ciudad, t. I, p. 291; Kaerger, La agricultura, p. 121; Miatello, Investigación, p. 485; LONFAT, Les colonies, p. 67.

80 Vázquez de la Morena, “Arado”, pp. 338-339; Miatello, Investigación, pp. 484 y ss.
} 
mucho más que los antiguos arados de mancera. Y a las necesidades de los arados se agregaron las de las segadoras. En consecuencia, se debió así ir conformando planteles de caballos de tiro adaptados para mover las nuevas máquinas. Los inventarios van mostrando avances significativos; en las colonias de Santa Fe, un informe de 1879 indicaba ya la existencia de 21962 "caballos de labor" contra 27421 bueyes. ${ }^{81}$ Para 1881 las cifras de ambos eran prácticamente idénticas: 32385 contra $32853 .^{82}$

Así, en el periodo comprendido entre 1865 y 1878 finalmente se lograron resolver los problemas principales de adaptación al cultivo extensivo y especializado en secano en las zonas de avance agrícola sobre la frontera pampeana. El periodo siguiente verá la expansión del mismo por fuera de los núcleos iniciales de las colonias, y será testigo al mismo tiempo de la vigencia del paquete tecnológico construido y de su paulatina pérdida de dinamismo.

EFICIENCIA, SELECTIVIDAD Y ESCALA:

LA AGRICULTURA A CAMPO, 1879-1900

Resueltos los puntos principales de la nueva tecnología cerealera, e incorporados al flujo circular de bienes y dinero entre proveedores y consumidores, la ampliación de la superficie agrícola era sólo cuestión de costos de oportunidad relativos. Desde 1880 (y en particular desde 1885) la abundancia de publicaciones destinadas a difundir los avances agrícolas se vuelve abrumadora, existiendo no sólo multitud de periódicos

81 García, Las colonias, p. 136. El valor de los bueyes era sin embargo el doble que el de los caballos, lo que puede indicar un poder de tracción menor para éstos.

82 Beck Bernard, La République Argentine, pp. 140-142; Coelho, Memoria, y LARGuía, Informe, pp. 8-10; datos de 1881 en García, Las colonias, cuadros. Sobre las características de los arados de asiento, Riccitelli, Arados, t. I, pp. 50-51, y atlas, figs. 22, 22 [b] y 23. 
especializados sino también una masa cada vez más destacada de folletos, recopilaciones de material censal, informes oficiales, consulares o privados, realizados por especialistas y con gran nivel de detalle. ${ }^{83}$ Toda esa masa de información circulaba profusamente entre los empresarios agrarios, pero también llegaba a los colonos y a los productores familiares, mediante las visitas y el diálogo con los inspectores de colonias o los representantes de organismos de difusión y propaganda agrícola. ${ }^{84}$ La formación de agrónomos, encarada desde 1887 con la creación del Instituto Agronómico de Santa Catalina, se amplió pronto al dictado de cursos de economía rural en los pueblos, difundiéndose métodos de cultivo más adecuados y realizándose las primeras tareas de extensión. ${ }^{85}$ Con el cambio de siglo comenzó la enseñanza agrícola ambulante, que utilizaba aulas y laboratorios instalados en vagones de tren. ${ }^{86} \mathrm{~A}$ ello debe agregarse, en la última década del siglo XIX, el creciente accionar de las compañías internacionales de maquinaria agrícola. ${ }^{87}$

83 Entre muchos otros, Newton y Llerena, Viajes; las investigaciones agrícolas de Huergo, Miatello, Raña y varios más encargadas por el Ministerio de Agricultura a inicios del siglo xx; y las de extranjeros, como Kaerger.

${ }^{84} \mathrm{La}$ ampliación progresiva de la circulación de información se evidencia por ejemplo en que el Boletín del Departamento de Agricultura pasó en 1884 de 500 a 2000 ejemplares mensuales, y era solo una entre varias publicaciones especializadas. Algunas de las acciones de extensión y asesoramiento de los ingenieros agrónomos gubernamentales están detalladas en MinisTERIO DE Agricultura, La experimentación agrícola.

${ }^{85} \mathrm{Al}$ Instituto de Santa Catalina, situado en la provincia de Buenos Aires, se agregaba el de Mendoza, fundado en 1881. Di Filippo, La enseñanza, pp. $27-47$.

86 Losson, Economía rural; Di Filippo, La enseñanza. El Ministerio de Agricultura editaba multitud de series prácticas en formato de folletos que se distribuían ampliamente en todo el país, a lo que se agregaba la aún más intensa labor propagandística de las empresas privadas.

87 Esta práctica llegó a hacerse masiva con el cambio de siglo; véase por ejemplo Wallace, Argentine. 
En resumen, la información fue difundiéndose hasta constituir un sistema de equilibrio, en el que las ganancias ya no dependían tanto de la introducción de innovaciones sino del agregado de factores. Es decir, la economía agrícola pampeana de la última década del siglo xix, pese a su acelerada expansión en la forma de continuos incrementos en la superficie cultivada, fue menos innovadora que la de los tiempos previos. En los primeros años del siglo xx, infinidad de alarmados analistas denostaban la "predatoria" agricultura cerealera, llevada a cabo por actores que, al calor de los ciclos de precios, solo se preocupaban por obtener más cantidad de granos, en detrimento de la calidad. ${ }^{88}$ Las críticas pueden haber sido exageradas, pero de todos modos transmitían el clima de la época: el conjunto de nuevas técnicas de cultivo estaba disponible para quien quisiera aplicarlo, junto con los servicios de maquinaria provistos a crédito por contratistas, y el crédito mismo por comerciantes rurales que fragmentaban las líneas de financiamiento de los grandes bancos. Se incorporaban así a la cadena productiva incluso inmigrantes recién llegados, sin fondos, sin propiedad inmueble que respaldara sus deudas, y aun sin experiencia previa. ${ }^{89}$

La clave en este periodo reside en la consolidación de un sector de grandes productores que encaraban en las zonas de mayor productividad una intensa racionalización de recursos: son ellos quienes experimentan con métodos de avanzada, buscando correr la frontera tecnológica. No podríamos aquí dar cuenta ordenada de todos esos esfuerzos, pero describiremos algunos de los correspondientes al segmento de la roturación. Uno de los más tempranos ensayos, derivado de la recurrente falta de medios de tracción animal, se centró en la labranza con maquinaria a vapor. Los métodos más útiles, consistentes en

88 Girola, Investigación agrícola, p. 148.

89 Muchos testimonios al respecto, entre ellos Miatello, Investigación, pp. $100-103,200$ y 372. 
sistemas de uno o dos motores locomóviles integrados a arados polirreja, podían abrir cinco o seis surcos a la vez, y hacerlo a mayor profundidad ( 40 o $50 \mathrm{~cm}$ ), lo que removía el subsuelo y aportaba sus nutrientes, ofreciendo rendimientos mayores..$^{90}$ Pero implicaban grandes costos en combustible, que pesaban fuertemente en una época de transición energética donde las escasas fuentes de energía local (leña, cara y de bajo poder calórico) iban dando paso al carbón de piedra (importado) para cubrir las necesidades motrices de la nueva maquinaria. ${ }^{91}$ Además, la fuerza de tracción necesaria para lograr acceder al subsuelo no se hacía tan necesaria, ya que hacia 1900 la mayor parte de las tierras cultivadas ofrecía todavía altos rendimientos sin necesidad de penetrar tan profundamente. El predominio de métodos extensivos no era la única opción, pero sí era preciso tenerla en cuenta en un contexto muy competitivo como el de entonces. Además, la apertura de solo 5 o 6 surcos por pasada era demasiado exigua para las vastas extensiones trabajadas en las explotaciones de gran o incluso mediano tamaño, resultando inconveniente la ecuación económica a pesar del ahorro en mano de obra y animales. ${ }^{92}$

El sistema que finalmente se afianzó, sobre todo desde 1900, fue el de tracción directa, consistente en enganchar varios juegos de arados a un motor a vapor que los arrastraba por medio de un balancín de cadenas, abriendo tantos surcos cuantas rejas

90 Cortés y Morales, Tesoro, t. I, pp. 136-141; Costa, Informe; Thome, "English Ploughs" y "The Amount".

${ }^{91}$ De todos modos, una parte de las máquinas, aún hacia 1905, aceptaba la variedad de combustible barato y alternativo disponible localmente: marlos de maíz, paja de trigo o lino, pasto, etc. Un ejemplo en Miatello, La aradura, p. 11.

92 Por lo demás, en las pampas los animales de tracción, vacunos y equinos, eran baratos, lo que constituía un desincentivo para emplear máquinas de vapor. Biraben, Memoria, p. 23. 
(o posteriormente discos) funcionaran..$^{93}$ Más simple, evitaba el sobrerrastreo sin mecanismos adicionales, permitía graduar la rapidez y profundidad de las labranzas dependiendo de la capacidad del motor; y además era práctico, ya que también se podía emplear en otras operaciones como la trilla y el desgrane, amortizando en menos tiempo el capital invertido. ${ }^{94}$ De todos modos, para amortizar el costo mayor (el locomóvil), lo ideal era poder utilizar la misma máquina de vapor para arar, cavar, zanjear, rastrillar, segar, cortar, engavillar, aventar y muchas otras tareas. ${ }^{95}$ Para el trabajo en tierras vírgenes, Hugo Miatello estimaba hacia inicios del siglo xx que los motores generalmente empleados, de 25 a 40 caballos, podían abrir, por pasada, de 10 a 20 surcos de unos 10 a $12 \mathrm{~cm}$ de profundidad. ${ }^{96} \mathrm{El}$ aumento de la eficiencia en la labranza puede juzgarse al ver que el incremento en la cantidad de arados apenas llega, entre 1888 y 1895, a la mitad del aumento porcentual de la superficie cultivada. ${ }^{97}$

El problema fue que, al consolidarse la labranza extensiva, a futuro los rendimientos entrarían en una fase decreciente si no se incorporaban nuevos métodos para sostenerlos y aun aumentarlos, variándose hacia una agricultura más intensiva. La coyuntura 1897-1901, en la que hubo resultados muy malos en la mayoría de los rubros agrícolas de todo el país, planteó crudamente la necesidad de renovar los caminos de explotación

\footnotetext{
${ }_{93}$ Miatello opinaba que era ideal con arados de tres discos. Para 1900 el sistema al parecer ya era conocido; aunque aún cuatro años más tarde se extendía con relativa lentitud. Miatello, La aradura, pp. 10-15.

94 Véase Biraben, Memoria, pp. 24 y ss.; también Kaerger, La agricultura, p. 154; un buen estudio sobre los pormenores de la aradura a vapor en Frank, Trigo y trabajo, pp. 127-149.

${ }^{95}$ Un detallado análisis de locomóviles de uso agrícola en Boletín del Departamento Nacional de Agricultura, t. XIV (jun. 1890), pp. 289 y ss.

${ }^{96}$ Este sistema se había generalizado bastante, según este autor. Miatello, Investigación, pp. 8 y ss.

${ }_{97}$ Reflexiones al respecto en KAERger, La agricultura, p. 911.
} 
del suelo. ${ }^{98}$ Los problemas de segunda generación, presentes sin duda en el ámbito local pero hasta entonces encubiertos por el constante agregado de tierras nuevas de altos rendimientos, se hicieron patentes y se combinaron con la acción de plagas y sequías.

La creación del Ministerio de Agricultura (1898) y el rápido desarrollo de oficinas de investigación, tanto estatales como privadas, fue parte de la respuesta ensayada. ${ }^{99}$ Así, durante las primeras décadas del siglo xx se va apagando lentamente el largo reinado del Barletta; adquieren peso variedades de mayor rendimiento experimentadas en las distintas oficinas agronómicas situadas en diversos puntos del área cultivable, y se logran las primeras hibridaciones, controladas y comercializadas desde semilleros gubernamentales o particulares. ${ }^{100}$ Pero la aún vigente incorporación de tierras nuevas continuó la tónica fundamentalmente extensiva de la expansión del gran cultivo (trigo, maíz y lino) al menos hasta 1910, y en las provincias y territorios que aún contaban con frontera abierta; desde ese año, las frecuentes oscilaciones en los precios de los principales cereales y el fuerte aumento de los costos fueron restando rentabilidad al sector cerealero en particular (y agrario en general), limitando su capacidad de captar capitales de inversión, y por tanto cambiar

${ }^{98}$ Los rendimientos en trigo, pero sobre todo en maíz, fueron muy pobres, con caídas dramáticas en algunas áreas. Las viñas y otras producciones regionales también se vieron afectadas. $Y$ a esos problemas se sumaron las plagas, en particular la langosta, y la sobreproducción (en especial de azúcar).

99 Véase al respecto DJEnderedjian, "El estado".

100 Los primeros experimentos en hibridación registrados oficialmente fueron encarados desde 1902 en el ámbito de las estaciones agronómicas del Ministerio de Agricultura; pero existieron también centros de ensayo en manos de particulares, en especial las compañías ferroviarias, interesadas en incrementar la producción agrícola para así generar carga. No hay datos sistemáticos sobre estos últimos, pero los ensayos ministeriales hasta 1915 se encuentran resumidos en Ministerio de Agricultura, La experimentación agrícola, pp. 17-31. Para un estudio más general, Harries y Ripoll, Semillas. 
definitivamente la base del esquema de explotación por otro más intensivo. Si bien los rendimientos por ha, medidos en el largo plazo, adquirieron un ritmo ascendente y la pérdida de grano se redujo, de todos modos esos fenómenos no alcanzarían a generar una nueva sinergia de rápida e intensa transformación tecnológica como la que en las pampas estaba por cerrarse. Afectado también por políticas adversas que buscaban promover la demanda agregada y el output del sector secundario, el sector agrario verá caer sobre sí el peso de normas dirigidas a garantizar su condición de proveedor de divisas, pero no su reconversión tecnológica. Varias décadas pasarán hasta que esta última tome finalmente cuerpo.

\section{CONCLUSIONES}

Desde el final del siglo xvirI hasta los inicios del xx la agricultura pampeana cambió por completo, no sólo en sus técnicas sino incluso en sus rasgos fundamentales: las superficies implantadas en promedio por unidad se multiplicaron más de diez veces, la especialización extensiva acaparó buena parte de las tierras aceleradamente incorporadas a uso agrícola, las condiciones ambientales de su desempeño variaron de manera radical, y se creó un paquete tecnológico completamente nuevo. El viejo arado criollo dio paso a instrumentos capaces de generar excedentes suficientes como para cubrir alrededor de un cuarto de la demanda mundial de alimentos básicos. La agricultura tradicional fue de ese modo transformada con particular profundidad desde mediados del siglo XIX, mediante el surgimiento de nodos de innovación cuya actividad e intercambios se fueron acelerando por medio de la acumulación de experiencia e información útil. El proceso, en el cual adquirieron un papel preponderante las colonias agrícolas formadas con inmigrantes extranjeros, las alejó progresivamente de los esquemas iniciales. La eficacia del nuevo paradigma puede apreciarse si pensamos que, entre 1864 y 1891, la superficie 
cultivada por habitante creció casi 50\%, pero la producción de trigo en toneladas per cápita se multiplicó tres veces y media.

Sin embargo, una vez resueltos todos, o al menos los principales elementos del nuevo paquete tecnológico, y extendido este a la generalidad de los actores, el peso de la modalidad extensiva adoptada derivó en dificultades para la entrada en una nueva etapa de agricultura más intensiva; la combinación con una coyuntura externa desfavorable marcada por la primera guerra mundial, y los diversos problemas macroeconómicos subsiguientes, no permitieron aquilatar la importante labor de investigación tanto pública como privada que generó un proceso por el cual, una vez alcanzada la frontera de las tierras cultivables en secano, se lograron estabilizar los rendimientos de las diversas áreas en un horizonte relativamente homogéneo, y aun aumentarlos y reducir las pérdidas. Todo ello chocaría, desde la década de 1930 hasta la de 1960, con aún más difíciles problemas macroeconómicos, que generaron fuertes caídas de la producción agrícola, que solo habrían de revertirse, otra vez, con cambios estructurales.

\section{SIGLAS Y BIBLIOGRAFÍA}

AGN, D Archivo General de la Nación, sección Manuscritos, sala IX, fondo Diezmos, Buenos Aires, Argentina.

AGN, TC Archivo General de la Nación, sección Manuscritos, sala IX, fondo Tribunal Civil, Buenos Aires, Argentina.

AGPSF, $G$ Archivo General de la Provincia de Santa Fe, fondo Gobierno, Santa Fe, Argentina.

AHMSI, DMP Archivo Histórico de la Municipalidad de San Isidro, fondo Documentos del Museo Pueyrredón. San Isidro, Provincia de Buenos Aires, Argentina.

AIM Archivo del Instituto Magnasco, fondo General, Gualeguaychú, Argentina.

Adelman, Jeremy, “The Social Bases of Technical Change: Mechanization of the Wheatlands of Argentina and Canada, 1890 to 1914", en Comparative Studies in Society and History, 34: 2 (1992), pp. 271-300. 
Alapin, Helena, Rastrojos y algo más. Historia de la siembra directa en Argentina, Buenos Aires, Teseo, Universidad de Belgrano, 2009.

Álvarez, Juan, Ensayo sobre la historia de Santa Fe, Buenos Aires, Malena, 1910.

Andreucci, Bibiana, Labradores de frontera. La Guardia de Luján y Chivilcoy 1780-1860, Rosario, Prohistoria, 2011.

Aragó, Buenaventura, El trigo y demás cereales, Madrid, Villaverde, 1881.

Banzato, Guillermo, La expansión de la frontera bonaerense. Posesión y propiedad de la tierra en Chascomús, Ranchos y Monte, 1780-1880, Bernal, Universidad Nacional de Quilmes, 2005.

Barsky, Osvaldo, Horacio Ciafardini y Carlos Cristiá, Producción y tecnología en la región pampeana, Buenos Aires, Centro Editor de América Latina, 1971.

BARsKy, Osvaldo y Julio DJENDEREDJIAN, La expansión ganadera hasta 1895. Historia del capitalismo agrario pampeano, Buenos Aires, Siglo Veintiuno Editores, t. I, 2003.

Bearzotti de NocetTi, Silcora, El proceso de mecanización agrícola en la Argentina, sus principales etapas, Buenos Aires, Instituto Nacional de Tecnología Agropecuaria, 1983.

BeCATtini, Giacomo, "Del distrito industrial marshalliano a la teoría del distrito contemporánea. Una breve reconstrucción crítica", en Investigaciones Regionales, 1 (2002), pp. 9-32.

Beck Bernard, Charles, La République Argentine, Lausanne, Delafontaine et Rouge, 1865.

Bianchi de Terragni, Adelina, Historia de Rafaela 1881-1940, Santa Fe, Colmegna, 1971.

Bidut, Vilma, Elsa Caula y Nora LiÑan, "Productores y producción en el partido de Rosario de los Arroyos a comienzos del siglo xix", en Papeles de Trabajo, 1 (1996), pp. 7-27.

Biraben, Alfredo, Memoria sobre agronomía, o estudio y descripción de un establecimiento agrícola-rural en la provincia de Buenos Aires, Buenos Aires, Peuser, 1881. 
Bjerg, María y Andrea Reguera (comps.), Problemas de la historia agraria. Nuevos debates y perspectivas de investigación, Tandil, Instituto de Estudios Histórico-Sociales "Profesor Juan Carlos Grosso", 1995.

Blancpain, Jean-Pierre, Les allemands an Chili (1816-1945), Colonia, Viena, Böhlau Verlag, 1974.

Bouchard, Gérard, Quelques arpents d'Amérique. Population, économie, famille au Saguenay, 1838-1971, Montreal, Boréal, 1996.

Brougnes, Auguste, Extinction du paupérisme agricole par la colonisation dans les provinces de La Plata, Bagnères-de-Bigorre, Dossun, 1855.

Brown, Johathan, Historia socioeconómica de la Argentina. 1776-1860, Buenos Aires, Di Tella, Siglo Veintiuno Editores, 2002.

Burgin, Miron, Aspectos económicos del federalismo argentino, Buenos Aires, Solar-Hachette, 1975.

BurmeIsTer, Hermann, Viaje por los estados del Plata: con referencia especial a la constitución física y al estado de cultura de la República Argentina, realizado en los años 1857, 1858, 1859 y 1860, Buenos Aires, Unión Germánica en la Argentina, 1943-1944.

Burmeister, Hermann, Description physique de la République Argentine, París, F. Savy, 1876.

Campolieti, Roberto, La ciencia y el arte de la colonización, Buenos Aires, Prudent \& Moetzel, 1916.

CARAvia, Antonio, Manual práctico del cultivador americano, Montevideo, Jaime Hernández, 1858.

Carrasco, Gabriel, Intereses nacionales de la República Argentina, Buenos Aires, Peuser, 1895.

Cassiolato, José E., Helena M. M. Lastres y María Lucía Maciel (eds.), Systems of Innovation and Development, Cheltenham, Edward Elgar, 2003.

Cerviño, Pedro, "Carta de D. Cipriano Orden Betoño en la que se proponen los medios de hacer útiles los terrenos desiertos que nos rodean", en Semanario de Agricultura, I: 14 y 15 (22 y 29 dic. 1802). 
Coelno, Guillermo, Memoria presentada al Excmo. Gobierno de la Provincia de Santa Fe por el señor Inspector de Colonias, Santa Fe, El Eco del Pueblo, 1874.

Collins, E. J. T., "The latter-day history of the draught ox in England, 17701964”, en Agricultural History Review, 58: 2 (dic. 2010), pp. 191-216.

Consejo Federal de Inversiones, Evaluación de los recursos naturales de la Argentina, Buenos Aires, 1962-1963.

Cortés Conde, Roberto, El progreso argentino. 1880-1914, Buenos Aires, Sudamericana, 1979.

Cortés y Morales, Balbino, Tesoro del campo, Madrid, Leocadio López, 1875.

Costa, Eduardo, Informe del Comisionado del Gobierno de la Provincia de Buenos Aires, Buenos Aires, Pablo E. Coni, 1871.

Custom House, Machinery. Account showing the several Countries to which MACHINERY has been exported, with the Official Value under each head, in each of the Years 1823, 1824, 1825, 1826 and 1827 [Londres, s/e, 1827].

Daireaux, Godofredo, Manual del agricultor argentino, Buenos Aires, Prudent \& Moetzel, 1901.

De Angelis, Pedro, Colección de obras y documentos relativos a la historia antigua y moderna de las provincias del Río de la Plata, Buenos Aires, Plus Ultra, 1969.

Deschamps, Jorge, Osvaldo Otero y Eduardo Tonni, "Cambio climático en la pampa bonaerense: las precipitaciones desde los siglos XviII al xx", en Documento de Trabajo, 109, Área de Estudios Agrarios, Universidad de Belgrano, Buenos Aires (2003), pp. 1-21.

Di Filıppo, Josefina, La enseñanza superior de las ciencias agropecuarias en la República Argentina, Buenos Aires, Fundación para la Educación, la Ciencia y la Cultura, 1984.

Di Lisia, María y Andrea Lluch (comps.), Argentina en exposición. Ferias y exhibiciones durante los siglos XIX y XX, Madrid, Consejo Superior de Investigaciones Científicas, 2009. 
Díaz Alejandro, Carlos, Ensayos sobre la historia económica argentina, Buenos Aires, Amorrortu, 1975.

Djenderedjian, Julio, "El Estado, presente. Aproximación a las políticas gubernamentales de desarrollo tecnológico, investigación y extensión rural en la Argentina de finales del siglo xIx e inicios del xx", en Revista de Historia Americana y Argentina, 49: 2 (2014), pp. 77-110.

DJenderedjian, Julio, La agricultura pampeana en la primera mitad del siglo XIX. Historia del capitalismo agrario pampeano, t. 4. Buenos Aires, Siglo Veintiuno Editores, Universidad de Belgrano, 2008.

Djenderedjian, Julio, "Roots of Revolution: Frontier Settlement Policy and the Emergence of New Spaces of Power in the Río de la Plata Borderlands, 1777-1810", en The Hispanic American Historical Review, $88: 4$ (2008), pp. 639-668.

DJenderedjian, Julio, Historia del capitalismo agrario pampeano, t. IV. La agricultura pampeana en la primera mitad del siglo XIX, Buenos Aires, Siglo Veintiuno Editores, Universidad de Belgrano, 2008.

Estado de Buenos Aires, Exposición agrícola-rural argentina de 1859, Buenos Aires, Imprenta Argentina, 1859.

Fienup, Darrell, Russell Brannon y Frank Fender, El desarrollo agropecuario argentino y sus perspectivas, Buenos Aires, Instituto Di Tella, 1972.

Fradkin, Raúl y Jorge Gelman, Rosas. La construcción de un liderazgo politico, Buenos Aires, Edhasa, 2015.

Frank, Rodolfo, Trigo y trabajo. Ganar el pan con el sudor de la frente, Buenos Aires, Dunken, 2017.

Galarza, Antonio, "Un nuevo puerto para Buenos Aires: la boca del río Salado como alternativa a los bloqueos portuarios en el Río de la Plata (18301850)", en Historia Crítica, 53 (2014), pp. 83-107.

Gallo, Ezequiel, La pampa gringa, Buenos Aires, Sudamericana, 1983.

Garavaglia, Juan, Pastores y labradores de Buenos Aires. Una historia agraria de la campaña bonaerense, 1700-1830, Buenos Aires, Ediciones de la Flor, 1999. 
García, José, "Las colonias de Santa Fe. Informe del Inspector, correspondiente al año 1879", en Boletín del Departamento Nacional de Agricultura, t. IV (1880), pp. 129-160.

García, Pedro Andrés, "Diario de un viaje a Salinas Grandes en los campos del sud de Buenos Aires”, en De Angelis, 1969, t. IV, pp. 1-72.

Girola, Carlos, Investigación agrícola en la República Argentina, Buenos Aires, Cía. Sud-Americana de Billetes de Banco, 1904.

Grenon, Pedro, La ciudad de Esperanza (Prov. de Santa Fe). Historia documentada e ilustrada, Córdoba, s/e, 1939.

Grigera, Tomás, Manual de agricultura, Buenos Aires, Imprenta de la Independencia, 1819.

Gschwind, Juan Jorge, Historia de San Carlos, Rosario, Instituto de Investigaciones Históricas, 1958.

Halperín Donghi, Tulio, "La expansión ganadera en la campaña de Buenos Aires (1810-1852)”, en Desarrollo Económico, 3: 1-2 (1963), pp. 57-110.

Harries, Adelaida y Carlos Ripoll, Semillas. Su evolución en nuestro país desde comienzos del siglo, Buenos Aires, Instituto Nacional de Tecnología Agropecuaria, 2000.

Holdich, Thomas, The Countries of the King's Award, Londres, Hurst and Blackett, 1904.

Iмноғ, Antonio, San Guillermo, un pueblo que crece bajo el signo del trabajo, San Guillermo, Santa Fe, s/e, 1991.

Isabelle, Arsène, Voyage à Buénos-Ayres et à Porto-Alègre, Havre, Morlent, 1835.

Johnson, Bjørn Harold, y Bengt-Åke Lundvall, "Promoting Innovation Systems as a Response to the Globalizing Learning Economy", en CassiolaTO, LASTRes y MAciel (eds.), 2003, pp. 143-172.

Johnson, Ross, A Long Vacation in the Argentine Alps or Where to Settle in the River Plate States, Londres, Richard Bentley, 1868. 
KAERgER, Karl, La agricultura y la colonización en Hispanoamérica. Los estados del Plata, Buenos Aires, Academia Nacional de la Historia, 2004.

Kauffman, Stuart, Investigations, Nueva York, Oxford University Press, 2000.

LaRguía, Jonás, Informe relativo a las colonias de la Provincia de Santa Fe, Rosario, El Independiente, 1879.

Lemée, Carlos, Tratado de ganadería y agricultura escrito especialmente para la República Argentina, Buenos Aires, Coni, 1882.

Lonfat, Gustave, Les colonies agricoles de la République Argentine décrites après cinq années de séjour, Lausanne, Genton, 1879.

Losson, Eduardo, Economía rural, Buenos Aires, La Plata, Peuser, 1888.

Marmier, Xavier, Lettres sur l'Amérique, París, Bertrand, 1851.

Martin de Moussy, Victor, Description Géographique et Statistique de la Confédération Argentine, París, Didot,1860-1864.

MARTIRÉN, Juan Luis, La transformación farmer. Colonización agrícola y crecimiento económico en la provincia de Santa Fe durante la segunda mitad del siglo XIx, Buenos Aires, Prometeo, 2016.

Martocci, Federico, "Cultivar al agricultor en la pampa seca. Generación y difusión de conocimientos agrícolas en las primeras décadas del siglo xx", en Mundo Agrario, 15: 28 (ago. 2014), pp. 1-24.

Metcalfe, J. Stan y Uwe Cantner, Change, Transformation and Development, Heidelberg, Physica-Verlag, 2003.

Miatello, Hugo, Investigación agrícola en la Provincia de Santa Fe, Buenos Aires, Cía. Sud-Americana de Billetes de Banco, 1904.

Miatello, Hugo, La aradura a vapor, Buenos Aires, Talleres de la Oficina Meteorológica Argentina, 1907.

Miguez, Eduardo, "La expansión agraria de la pampa húmeda (1850-1914). Tendencias recientes de su análisis histórico", en Anuario IEHS, 1 (1986), pp. 89-119. 
Ministerio de Agricultura, La experimentación agrícola en la República Argentina. Antecedentes históricos. Buenos Aires, Talleres Gráficos del Ministerio de Agricultura de la Nación, 1915.

Mokyr, Joel, Technological Creativity and Economic Progress, Oxford, Oxford University Press, 1990.

Müller, J. T. Novísimo diccionario universal de agricultura, Barcelona, Maucci, 1900.

Napp, Ricardo, La República Argentina, Buenos Aires, Sociedad Anónima, 1876.

Newton, Ricardo y Juan Llerena, Viajes y estudios de la Comisión Argentina sobre la Agricultura, Ganadería, Organización y Economía Rural, Buenos Aires, La República, 1882-1884.

Nicolorich, Luis, "La Candelaria”, colonia de d. Carlos Casado. Su fundación, progreso y prosperidad actual, Rosario, La Opinión Nacional, 1872.

Oggier, Gabriel y Emilio Jullier, Historia de San Jerónimo Norte, Rosario, Apis, 1984.

Pellegrini, Carlos, “Arados”, en Revista del Plata, 2 (oct. 1853), pp. 14-15.

PÉrez, Carlota, "Structural change and the assimilation of new technologies in the economic and social systems", en Futures, xv: 4 (1983), pp. 357-375.

Pérez Castellano, José Manuel, Observaciones sobre agricultura, Montevideo, A. Barreiro y Ramos, 1914 [escrito en 1814].

Perkins, Guillermo, Las colonias de Santa Fe, Rosario, El Ferro-Carril, 1864.

Petriella, Dionisio y Sara Sosa Miatello, Diccionario biográfico italoargentino, Buenos Aires, Asociación Dante Alighieri, 2002.

PucCIARelli, Alfredo, El capitalismo agrario pampeano, 1880-1930, Buenos Aires, Hyspamérica, 1986.

Riccitelli, José, Arados de reja y vertedera, Buenos Aires, eudeba, 1967.

Roche, Jean, La colonisation allemande et le Rio Grande do Sul, París, Institut des Hautes Études de l'Amérique Latine, 1959. 
Rogers, Everett M., Diffusion of Innovations, Nueva York, The Free Press, 1983.

Rosas, Juan Manuel de, Instrucciones para los encargados de las chacras, Buenos Aires, La Era, 2002.

Rutter, William, Wheat-growing in Canada, the United States and the Argentine Including Comparisons with Other Areas, Londres, Adam and Charles Black, 1911.

SARTELLI, Eduardo, "Del asombro al desencanto. La tecnología rural y los vaivenes de la agricultura pampeana”, en BJERG y REgUera, 1995, pp. 125-154.

Sastre, Marcos, El Tempe argentino, Buenos Aires, Ostwald, 1881.

Sbarra, Noel, Historia de las aguadas y el molino, Buenos Aires, eudeba, 1973.

Scobie, James, Revolución en las pampas. Historia social del trigo argentino, 1860-1910, Buenos Aires, Solar, Hachette, 1968.

SESTO, Carmen, Una genética en carnes de alta productividad: el refinamiento del vacuno en la provincia de Buenos Aires, La Plata, Fundación Banco de la Provincia de Buenos Aires, 2005.

Seyferth, Giralda, A colonização alemã no vale do Itajaí-Mirim. Um estudo de desenvolvimento econômico, Porto Alegre, Movimento, 1974.

Simors, Domingo, "El trigo en la provincia de Buenos Aires", tesis de agronomía, La Plata, Imprenta y litografia Solá/Sesé, 1893.

SinclaIr, John, L'Agriculture pratique et raisonnée, París, Huzard, 1825.

Tноме, Samuel, "English Ploughs and Ploughing”, en The Farmer's Magazine, $\operatorname{xIx}$ (ene.-jun. 1861), pp. 141-148.

Thome, Samuel, “The Amount of Power Applied in Steam Ploughing”, en The Farmer's Magazine, XIx (ene.-jun. 1861), pp. 473-480.

Troisi, Enrico, L' Argentina agricola. Cordova e le sue colonie, Buenos Aires, Córdoba, Aveta, "La Minerva”, 1904-1905. 
Vanhaute, Eric, Richard Paping y Cormac Ó Gráda, “The European subsistence crisis of 1845-1850: a comparative perspective", en International Economic History Congress, Helsinki (2006), pp. 3-17.

VÁzquez de la Morena, Manuel, “Arado 'solid confort' sulky”, en Boletín del Departamento Nacional de Agricultura, x (1886), pp. 338-339.

Wallace, Richard, Argentine Shows and Livestock, Edimburgo, Londres, Oliver and Boyd, Marshall \& Co., 1904.

Wilcken, Guillermo, Las colonias. Informe sobre el estado actual, Buenos Aires, Sociedad Anónima, 1873.

Zeballos, Estanislao, Descripción amena de la República Argentina, Buenos Aires, Peuser,1883, t. II. 
